\title{
Treatment of Class III malocclusion in the primary and early mixed dentition using the Kiebach Appliance and Protraction Facemask
}

\author{
Erica W. Reed \\ West Virginia University
}

Follow this and additional works at: https://researchrepository.wvu.edu/etd

\author{
Recommended Citation \\ Reed, Erica W., "Treatment of Class III malocclusion in the primary and early mixed dentition using the \\ Kiebach Appliance and Protraction Facemask" (2011). Graduate Theses, Dissertations, and Problem \\ Reports. 3437. \\ https://researchrepository.wvu.edu/etd/3437
}

This Thesis is protected by copyright and/or related rights. It has been brought to you by the The Research Repository @ WVU with permission from the rights-holder(s). You are free to use this Thesis in any way that is permitted by the copyright and related rights legislation that applies to your use. For other uses you must obtain permission from the rights-holder(s) directly, unless additional rights are indicated by a Creative Commons license in the record and/ or on the work itself. This Thesis has been accepted for inclusion in WVU Graduate Theses, Dissertations, and Problem Reports collection by an authorized administrator of The Research Repository @ WVU. For more information, please contact researchrepository@mail.wvu.edu. 


\section{TREATMENT OF CLASS III MALOCCLUSION IN THE PRIMARY AND EARLY MIXED DENTITION USING THE KIEBACH APPLIANCE AND PROTRACTION FACEMASK}

Erica W Reed, DDS

A THESIS

Submitted to:

The School of Dentistry

at West Virginia University

in partial fulfillment of the requirements

for the degree of

Master of Science

In

Orthodontics

Peter Ngan, D.M.D., Chair

Chris Martin, D.D.S., M.S.

Thomas Razmus, D.D.S., M.S.

Department of Orthodontics

Morgantown, West Virginia

2011 


\section{ABSTRACT \\ Treatment of Class III Malocclusion in the Primary and Early Mixed Dentition Using the Kiebach Appliance and Protraction Facemask}

Erica W. Reed, DDS

Objectives: To evaluate the short and long-term results of using a Modified Hyrax Expander with Protraction Facemask at an early age. Methods: Twenty three patients were treated with Dr. Kiebach's Modified Hyrax Expander and Protraction Facemask at an early age. Lateral Cephalograms were taken at three time points: pre-treatment (T1), post-treatment (T2), and 2 years post-treatment (T3) and evaluated using cephalometric analysis. Results: Statistically significant results were found for all three time points: T2-T1, T3-T2, and T3-T1. The Palatal Plane, Mandibular Plane, and the Occlusal Plane were the only values to show non-significant results throughout the three time points. The overjet and correction for T2-T1 was 52\% dental and $48 \%$ skeletal. The molar correction for T2-T1 was $115 \%$ skeletal and $-15 \%$ dental. The T3-T2 findings for overjet correction showed a negative $2 \mathrm{~mm}$ skeletal correction, but a $1.9 \mathrm{~mm}$ dental correction. The same was true for the molar correction for T3-T2. There was a negative 2.16 $\mathrm{mm}$ skeletal relapse, but a positive $1.92 \mathrm{~mm}$ dental correction. Evaluating the overall change using T3-T1, the results showed a mostly dental correction for overjet at $105 \%$ and a molar correction that was $113 \%$ dental. Overall, the maxilla moved forward $4.2 \mathrm{~mm}$ while the mandible moved forward $4.4 \mathrm{~mm}$. Conclusions: Treatment at a young age using a Modified Hyrax Expander with Protraction Facemask is successful in treating a Class III malocclusion. The correction is both skeletal and dental. 


\section{DEDICATION}

To my husband Jason Lawrence for always being there for me and lending me a supporting hand. You give me strength to push forward when I am weary. You believed in me when I didn't believe in myself. I'm so glad I get to come home to you every day. You are the light of my life.

To my parents, James and Eleanor Reed, for being such good role models in my life. You are the best parents. You've sacrificed so much to help me get to where I am today. You are an inspiration in my life. I could not have done this without you. Thank you for all the support and the phone calls!

To my grandfather Raymond Warren who taught me many things, but above all, that hard work always pays off. Thank you for instilling in me the importance of education and all your help while I was working on mine. I'll never forget your great stories.

To my sister Vanessa Bennett who always took up for me and taught me fight for what is right. I would not have had the courage to complete this task without your example. Believe it or not, but I have been trying to catch up with you my whole life. Keep me reaching!

To my brother Robert Reed who has taught me to never stop and never give up. You are an inspiration to me. I may never run a marathon, but I know I could because you lead by example.

To my in-laws Patricia Alexander, Aaron Alexander, Patricia Lawrence, Gene Lawrence, John Loving, Marvine Loving, Page Alexander, and Joe Alexander for accepting me into your wonderful family. Thank you.

To my Great Aunt El and Uncle Ban for being so supportive in my educational endeavors. Thank you also for being such great examples of generosity and healing to others. You both are missed.

To my grandparents who are not with us today, Eleanore Warren, Lucy Warren, Mama Tobe and Daddy Tobe; the love and support began with you and you are missed.

To my church family at St. Mark's Episcopal Church for helping raise me. Your love has stayed with me and been an inspiration during the tough times.

To my teachers who took their time to teach and make a difference in my life. I would not be here without your hard work and dedication.

To my cats Sebastian and Penelope for being the cutest, most loving pets I could ask for. You cheer me up when I am down. I look at my rescue cats and appreciate the roof over my head and the food in my stomach. 


\section{ACKNOWLEDGEMENTS}

Dr. Peter Ngan - For being a wonderful mentor and advisor. You have built the best residency program in the world. Your dedication to orthodontics and teaching has given me an invaluable gift I will pass on to my patients and, hopefully, future residents at WVU.

Dr. Chris Martin - For also being a wonderful mentor and advisor. I will remember your kindness and support over the past 3 years. I will always be your vice president.

Dr. Thomas Razmus - For your help with my thesis. Thank you for giving your time and being a friendly face across the hallway.

Dr. Thomas Kiebach - For allowing me to use your clinical records for my thesis. You were motivational and uplifting throughout this process.

Part time Faculty members: Drs. Tremont, Kirsch, McFarland, Hazey, Jarrett, Foley, Boyles, Sebbahi, and Gilmore for your pearls of wisdom that I will take with me through the remainder of my career. Your dedication to the program and profession is remarkable. Thank you for kindness and everything you have done for me over the years. It was much appreciated.

Drs. Larry and Will Andrews for passing on your knowledge and expertise in orthodontics. Thank you for being so welcoming to WVU residents!

Staff members Karen, Leona, Carrie, Hillary and Joyce for lending me a helping hand and for always being there to listen.

Rob VanLaecken - For being such a wonderful classmate who understood the stresses and was a light-hearted companion through thick and thin. Thanks for being a great friend. You are a wonderful person and hard worker and I am proud to call you my pier.

Maggie Adams - We have been through thick and thin as well and I'm happy to share the milestones we have achieved together. You have been a wonderful friend and confidant. I truly could not have made it through without you! You were always one step (or let's face it...several steps) ahead of me and that's exactly what I needed. Here's to many more years of friendship!

My fellow residents Thuy, Rajia, Mike B, Mike M, Dean, Colin, Jung Mee, Holly, Ronnie, Doyong, Chad and Alice for all the great times we shared. Thank you for your help along the way. Best wishes to all of you! 


\section{TABLE OF CONTENTS}

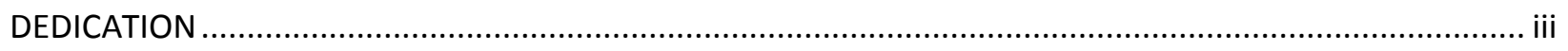

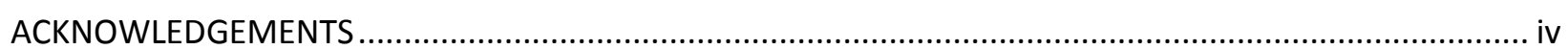

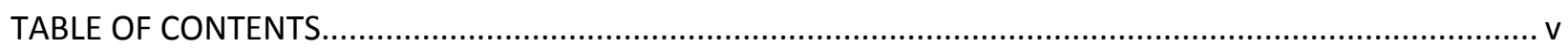

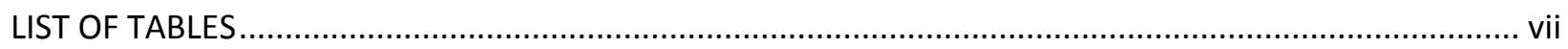

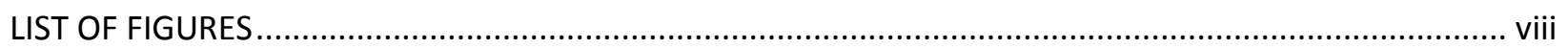

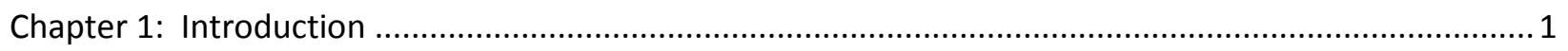

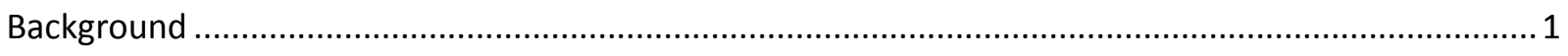

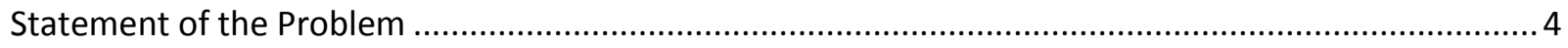

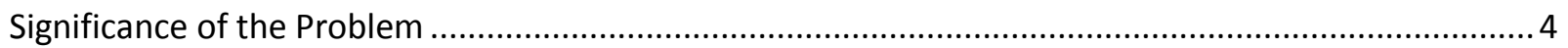

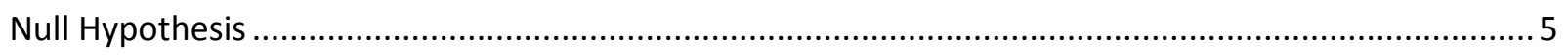

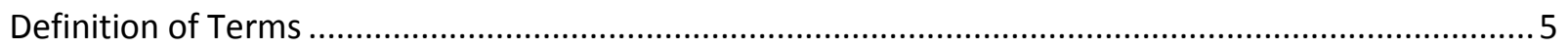

Assumptions

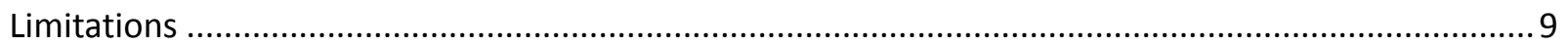

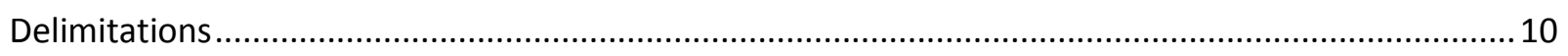

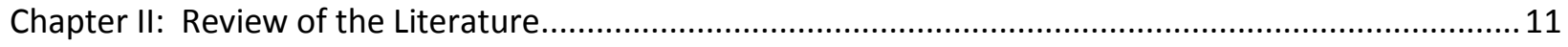

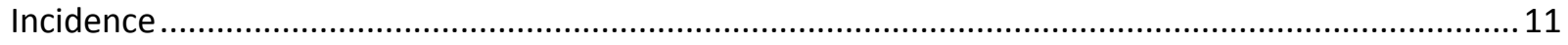

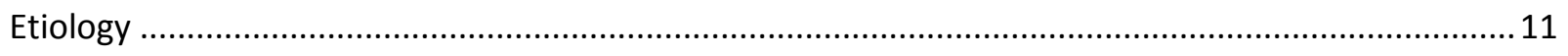

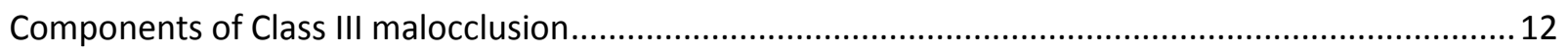

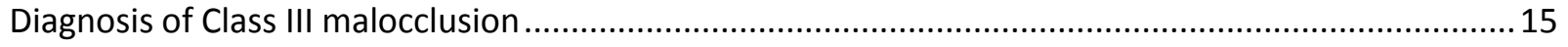

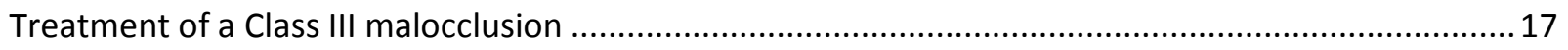

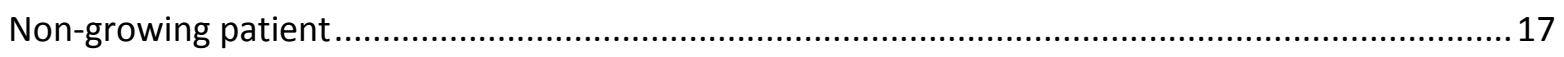

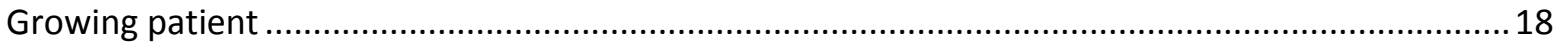

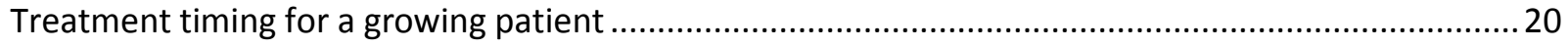

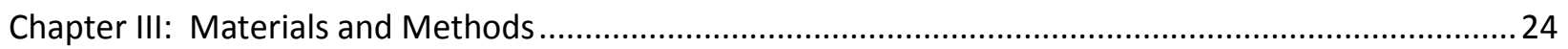

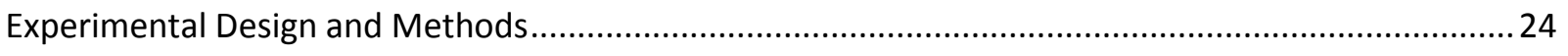

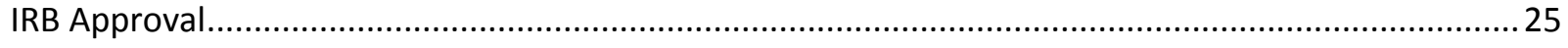

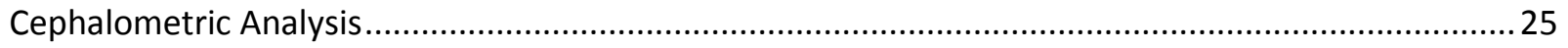

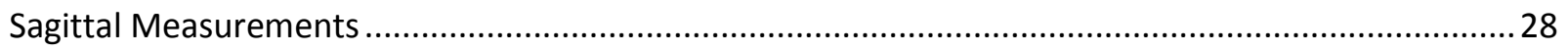

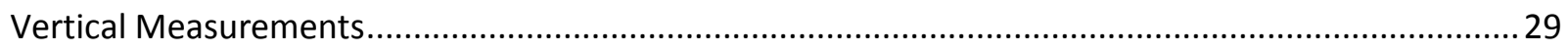

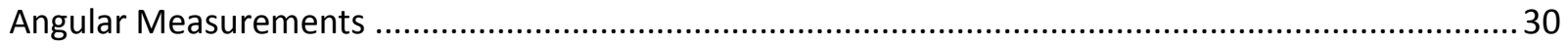




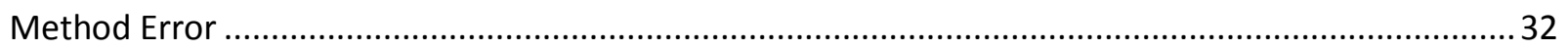

Evaluation of Overjet and Molar Relationship Correction............................................................. 34

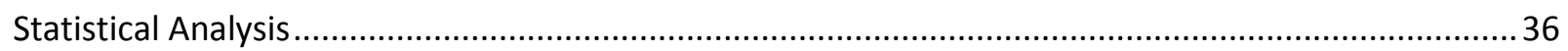

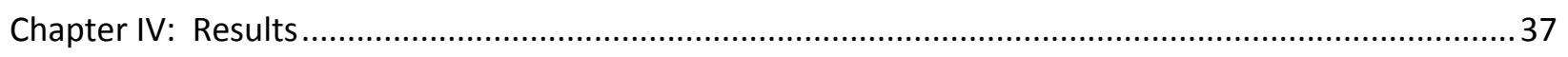

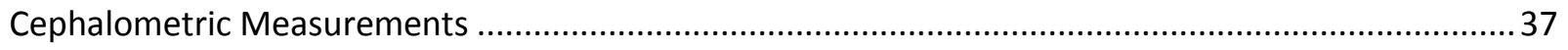

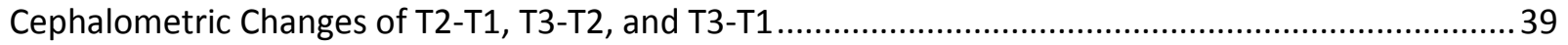

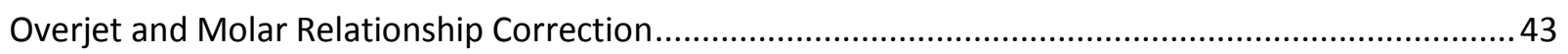

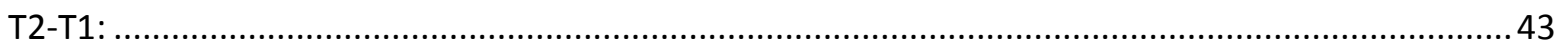

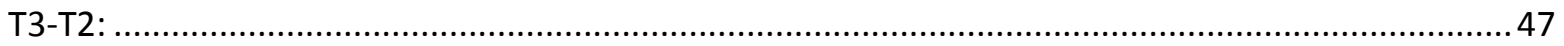

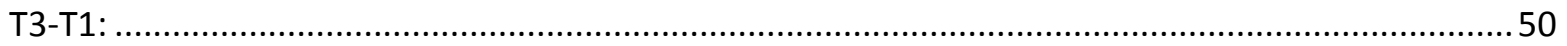

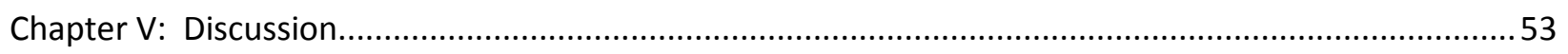

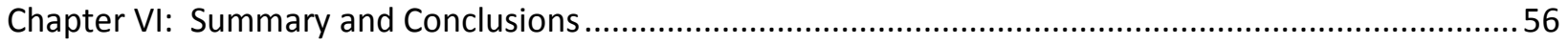

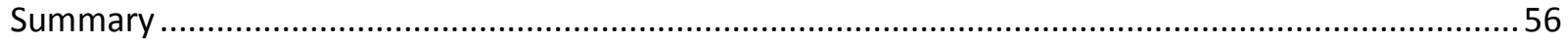

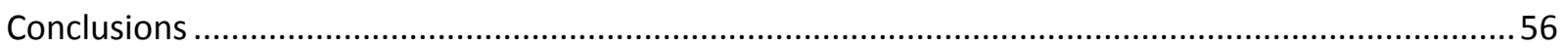

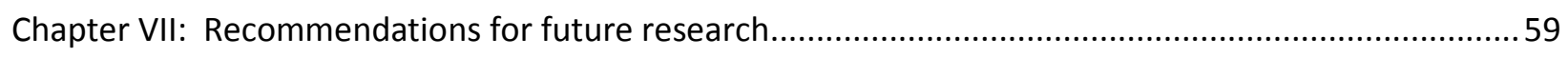

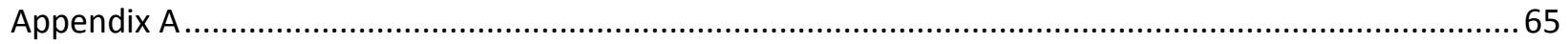




\section{LIST OF TABLES}

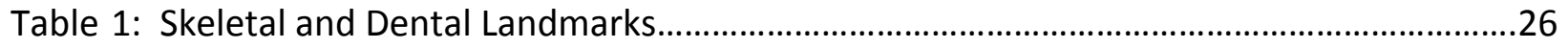

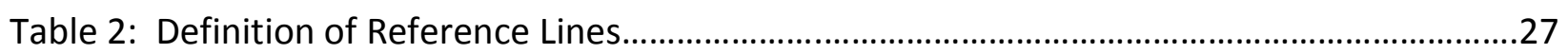

Table 3: Sagittal Measurements of variables 1-9.........................................................................29

Table 4: Vertical Measurements of variables 10-16......................................................................30

Table 5: Angular Measurements of variables 17-25......................................................................32

Table 6: Reliability Coefficients for all variables at T1, T2, and T3.........................................33

Table 7: Calculation of Overjet and Molar Relationship Changes.................................................34

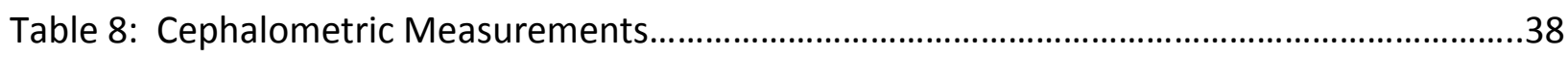

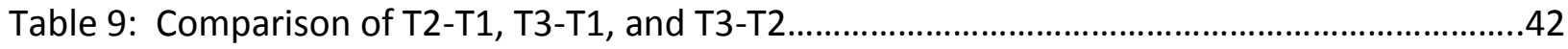




\section{LIST OF FIGURES}

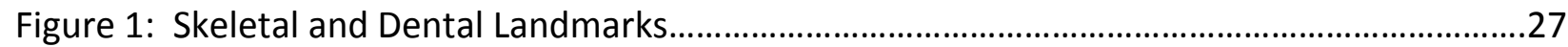

Figure 2: The reference grid used in the sagittal cephalometric analysis.....................................28

Figure 3: The reference lines and measuring points used in the vertical analysis.........................30

Figure 4: The reference lines and measuring points used for angular analysis.............................31

Figure 5: Components of Overjet Correction T2-T1 ....................................................................

Figure 6: Components of Molar Correction T2-T1 ..................................................................44

Figure 7: Pitchfork Analysis for Overjet and Molar Correction T2-T1...........................................46

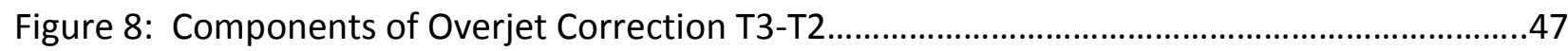

Figure 9: Components of Molar Correction T3-T2 …...................................................................48

Figure 10: Pitchfork Analysis for Overjet and Molar Correction T3-T2........................................49

Figure 11: Components of Overjet Correction T3-T1 ...................................................................50

Figure 12: Components of Molar Correction T3-T1..................................................................51

Figure 13: Pitchfork Analysis for Overjet and Molar Correction T3-T1 ........................................52 


\section{Chapter 1: Introduction}

\section{Background}

The prevalence of a Class III malocclusion is estimated to be about $5.6 \%$ of United States population. ${ }^{1}$ Traditional treatment for these individuals include: orthodontic camouflage, orthopedic correction using functional appliances, and orthognathic surgery. Early orthopedic therapy including an RPE and facemask can help patients with retrognathic maxillas if it is provided early. A retrusive maxilla is the underlying cause of a Class III malocclusion in $57 \%$ of patients. $^{2,3}$ In 42 percent of class III maloclussions mandibular excess is the primary problem. ${ }^{4}$

Although a Class III malocclusion has a relatively low prevalence, it presents as a challenging orthodontic problem. ${ }^{5}$ Historically, the Class III malocclusion was viewed as a problem of the mandible. A Class III malocclusion and mandibular prognathism were virtually synonymous. ${ }^{6}$ Management usually involved chincup appliances to restrain mandibular growth, camouflage techniques to advance maxillary incisors and retract mandibular incisors, or wait until growth ceased to pursue orthognathic surgery. ${ }^{7}$ Many studies have found that the primary etiology in a Class III malocclusion is, however, maxillary deficiency. Protraction facemask in the treatment of Class III malocclusions with maxillary deficiency has become an acceptable procedure among the orthodontic profession.

Facemask therapy is often supplemented with maxillary expansion. Midface orthopedic expansion has been recommended for use in conjunction with protraction forces on the maxilla because it supposedly disrupts the circummaxillary sutural system and facilitates the 
orthopedic effect of the facemask. ${ }^{8-11}$ There is evidence that maxillary expansion alone can be beneficial in treating Class III malocclusions, especially in borderline malocclusions. Haas reported that palatal expansion produces a forward and downward movement of the maxilla by affecting the intermaxillary and cirummaxillary sutures and the disruption of these sutures may help initiate cellular response in the sutures, allowing for a more positive reaction to protraction force.$^{9,10} \mathrm{RME}$ is also helpful in these patients because maxillary retrognathic patients also have posterior crossbites due to a deficiency in the transverse dimension as well.

Recommendations on the optimal time to treat a child with a combination of palatal expansion and facemask therapy have been based primarily on clinical impressions. The recommended age to begin treatment is between the age of 6 and 8 years after the maxillary permanent first molars and incisors have erupted. ${ }^{12-14}$ Studies have employed biologic indicators such as chronological age, stage of dental development or skeletal age to determine the impact of age on orthopedic treatment. ${ }^{8,12,15-20}$ It was found that early treatment, sometimes beginning as young as age 4 , can be effective for orthopedic correction of Class III malocclusions. ${ }^{12}$ Several studies found younger patients more responsive to orthopedic correction. Compliance is also less of an issue at this early age.

Various expansion appliances have been used as anchorage devices for maxillary protraction. The problem with using bands is breakage around the solder joints. A heavy 0.036 " wire is usually soldered to the buccal side of the molar band and extends forward to the canine area for protraction. A new design that utilizes a stainless steel crown and a removable arm for maxillary protraction may overcome this problem. This arm resists deformation and 
fracture while also providing rigidity. The stainless steel crowns keep the anterior teeth away from occlusion. This design is particularly suitable for patients in the primary dentition.

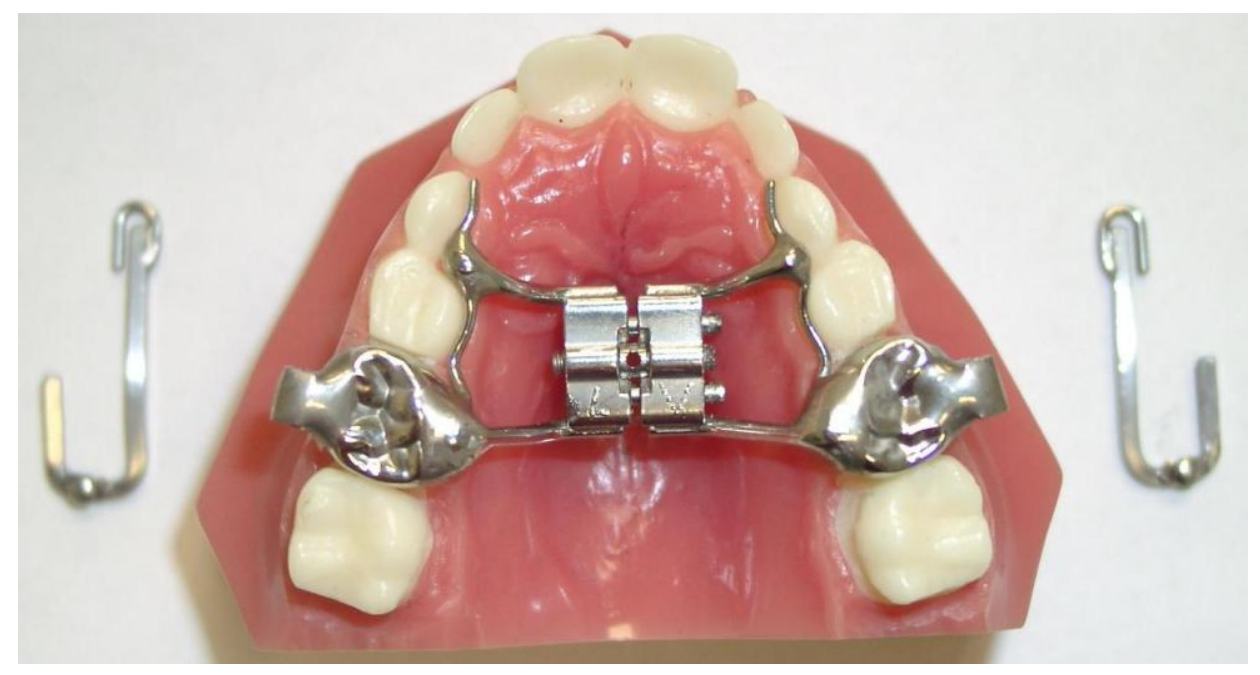

The objective of this study was to conduct an observational retrospective study to determine the immediate and long term skeletal and dental effects of this new anchorage device used in conjunction with a protraction facemask. The experimental group consisted of 23 patients treated with Dr. Kiebach's Modified Hyrax appliance and protraction facemask therapy at an early age. Lateral cephalograms were taken before treatment (T1), after treatment (T2), and approximately 2 years post-treatment (T3). A custom cephalometric analysis as described by Byork ${ }^{21}$ and Pancherz ${ }^{22}$ was used to determine the amount of skeletal and dental correction. Data will be analyzed using a paired t-test. 


\section{Statement of the Problem}

The purpose of this research project is to determine the skeletal and dentoalveolar changes in Class III patients treated using Dr. Kiebach's Modified Hyrax Expander and facemask therapy in the primary and early mixed dentition.

\section{Significance of the Problem}

For young Class III patients with a retrusive maxilla, the treatment of choice is maxillary expansion combined with a protraction facemask. The timing for this treatment is traditionally between the ages of six and eight years after the maxillary permanent first molars and incisors have erupted. Recent studies have shown that the earlier treatment begins, the more the maxilla will protract.

Dr. Kiebach advocates early treatment and has designed a Modified Hyrax expander which utilizes Stainless Steel crowns and laser welded arms that prevent breakage and provide more anchorage for use in the primary and early mixed dentition. The stainless steel crowns also serve as a bite plate to reduce any interference from the occlusion while protracting. This study will determine how much skeletal movement patient's treated in this manner will receive and document the stability of the movements at this young age. 


\section{Null Hypothesis}

1. There were no significant sagittal changes in patients treated with Dr. Kiebach's Modified Hyrax Expander and facemask therapy.

2. There were no significant vertical changes in patients treated with Dr. Kiebach's Modified Hyrax Expander and facemask therapy.

3. There were no significant angular changes in patients treated with Dr. Kiebach's Modified Hyrax Expander and facemask therapy.

\section{Definition of Terms}

1. Maxillary expansion: Separation of the two halves of the maxilla achieved in the growing individual with the use of and orthopedic expansion device.

2. Maxillary protraction: The orthopedic anterior and downward repositioning of the maxilla achieved in the growing individual with the use of an orthopedic protraction facemask appliance.

3. Protraction facemask: An extraoral appliance used to exert a forward and downward vector of force on the maxilla. Also referred to as protraction headgear.

4. Class III malocclusion: That relationship in which the buccal groove of the mandibular first permanent molar articulates anteriorly to the mesiobuccal cusp of the maxillary first permanent molar. A mesial relationship of the lower first molar to the upper and/or a distal relationship of the upper first molar to the lower. 
5. Skeletal Class III malocclusion: Skeletal relationship in which either the mandible is prognathic, the maxilla is retrognathic, or a combination of the two.

6. Pseudo Class III malocclusion: Relationship in which a Class I skeletal pattern, normal facial profile, and Class I molar relation may occur in centric relation, but a Class III skeletal and dental pattern are observed in centric occlusion.

7. Centric occlusion: The relationship between upper and lower teeth in normal full functional closure

8. Centric relation: The relation between upper and lower teeth when both mandibular condyles are fully seated in their fossa in optimum functional positions.

9. Cephalogram: A term sometimes used as a synonym for cephalometric radiograph.

10. Cephalometric analysis: An evaluation of dental and related skeletal relationships based on measurements of cephalometric radiographs.

11. Cephalometric radiograph: A radiograph of the head made with precise reproducible relationships between x-ray source, subject and film. The generally accepted distances between $\mathrm{x}$-ray source and the center of the subject are 5 feet or 150 centimeters. The distance between subject and film is usually $15 \mathrm{~cm}$, but may be standardized at different value or varied with patient size and recorded for each exposure.

12. Cephalometric tracing: A tracing of selected structures from a cephalometric radiograph, made on translucent drafting paper or digitized on computer software for purposes of measurement and evaluation.

13. Comprehensive orthodontic therapy: A coordinated approach to improvement of the overall anatomic and functional relationships of the dentofacial complex, as opposed to 
partial correction with more limited objectives such as cosmetic improvement.

Comprehensive orthodontic treatement, usually, but not necessarily, utilizes fixed orthodontic attachments as one treatment modality. May be coordinated with adjunctive procedures directed at malrelationships within the entire dentofacial complex.

14. Crossbite: An abnormal relationship of a tooth or teeth to the opposing teeth, in which normal buccolingual relationships are reversed.

15. Deep bite: Excessive overbite; closed bite

16. Distal: A direction oriented along the dental arch away from the dental midline; right or left in the anterior segment, posteriorly in the buccal segments.

17. Mesial: Toward or facing the midline, following the dental arch. Used to describe surfaces of teeth as well as direction.

18. Labial: of or pertaining to the lip. Also used to identify a surface facing the lips or a direction toward the lips.

19. Lingual: Of or pertaining to the tongue. Used to describe surfaces and directions facing the tongue.

20. Malocclusion: A deviation in intramaxillary and/or intermaxillary relations of teeth that presents a hazard to the individual's well-being. Often associated with other dentofacial deformities.

21. Mixed dentition: The developmental stage during which both deciduous and permanent teeth are present in the mouth. 
22. Occlusion: The relationship of the maxillary and mandibular teeth as they are brought into functional contact.

23. Open bite: A malocclusion in which some teeth cannot be brought into functional contact with opposing teeth.

24. Overbite: Vertical overlapping of upper teeth over lower teeth usually measured perpendicular to the occlusial plane.

25. Overjet: Horizontal projection of upper teeth beyond the lower teeth, usually measured parallel to the occlusal plane.

26. Prognathic: Forward relationship of the mandible relative to the craniofacial skeleton.

27. Retrognatic: The condition of the maxilla or mandible that is posterior to its normal relationship with other facial structures.

28. Retrusion: Teeth and/or jaw posterior to their normal positions.

29. Proclination: Anterior angulation of anterior teeth, as opposed to protrusion, which indicates positional variation.

30. Tipping: Tooth movement, either spontaneous or therapeutic, in which the angulation of the long axis of the root is changed.

31. Facial concavity: A term applied to the analysis of a profile. The shape is described as an inwardly rounded curve from the forehead to the lips to the chin. A concave facial profile is often associated with a Class III malocclusion.

32. Hyrax expander: Commonly used type of banded rapid maxillary expansion appliance. Bands are placed on the maxillary first molars and first premolars or primary molars. 
The expansion screw is located in the palate in close proximity to the palatal contour.

Buccal and lingual support wires also may be added for rigidity.

\section{Assumptions}

1. It is assumed that the lateral cephalograms were taken with the teeth in centric relation.

2. It is assumed that each child achieved sutural separation with the expander before using the protraction facemask.

3. It is assumed that each patient wore the facemask for at least 12 hours per day.

\section{Limitations}

1. Inconsistency of records due to exfoliation of teeth during treatment. Serial cephalograms will be taken over time. Treatment begins in the primary dentition and exfoliation of primary incisors during treatment time will be a source of uncontrolled error in the treated group.

2. Since different $x$-ray units were used to collect data all the magnification errors were accounted for.

3. Cooperation differences between patients such as length of time each child wears the facemask appliance daily.

4. Samples were not selected at random. 
5. The total sample was limited to 23 patients due to the availability of records.

6. The T3 follow up cephalograms were taken at different time intervals.

7. The $\mathrm{T} 2$ radiographs were taken at different time intervals.

\section{Delimitations}

1. One researcher performed all cephalometric tracings and measurements.

2. Patients with craniofacial anomalies were excluded from the study.

3. Patients were limited to those in a primary dentition or early mixed dentition.

4. The experimental group was limited to patients who had acceptable quality radiographs for the various time points of the study. 


\section{Chapter II: Review of the Literature}

\section{Incidence}

The Prevalence of Class III malocclusions vary among different ethnicities. In Caucasians, the incidence ranges from $1-4 \%$ of the population. ${ }^{23-26}$ Asian societies have a higher incidence of maxillary deficiency and, therefore, a higher incidence of Class III malocclusions. The incidence ranges between $4 \%$ and $5 \%$ among the Japanese and $4 \%$ and $14 \%$ among the Chinese. ${ }^{23,27,28}$ The prevalence is approximately $3-6 \%$ in the U.S. black population. Class III malocclusions are more prevalent in Hispanic populations than in African or Caucasian groups. ${ }^{13}$

\section{Etiology}

The etiology of malocclusions has been studied for many years. Some studies conducted to learn about the etiology of malocclusions compared identical twins, fraternal twins, and ordinary siblings. The difficulty in these studies was to confirm that the environments were the same for both members of a twin pair. Summarizing a number of research investigations of this type, Lauweryns et al. concluded that about $40 \%$ of the dental and facial variations that lead to malocclusion can be attributed to hereditary factors. ${ }^{29,30}$ One of the best known examples of a hereditary Class III malocclusion is that of the Hapsburg's, a European royal family. The families mandibular prognathism became known as the Hapsburg jaw because it recurred over many generations. ${ }^{30}$ A prognathic mandible was evident in $83 \%$ of the 40 family members whom records were available. ${ }^{31}$ 
Harris and Johnson also concluded that the heritability of craniofacial or skeletal characteristics was relatively high, but that the dental characteristics was low. ${ }^{30}$ Dental characteristics are caused more from environmental factors; such as tongue posturing and other habits. Environmental factors, although more rare, can cause Class III malocclusions. Environmental influences during growth and development consist largely of pressures and forces related to physiologic activity. How you chew and swallow place pressures against the jaws and teeth that can affect how jaws grow and teeth erupt in to the jaws. ${ }^{30}$ An equilibrium is formed between soft and hard tissues. A large tongue, perhaps in a patient with a thyroid disorder, can cause the development of mandibular prognathism due to the mandible being postured forward at all times. ${ }^{30}$ This constant distraction of the mandibular condyles may cause excessive mandibular growth in these patients. Mandibular size may also be affected by functional mandibular shifts due to respiratory needs. A mouth-breather's tongue tends to be flat and anteriorly displaced, resulting in the mandibular arch widening laterally and anteriorly.

\section{Components of Class III malocclusion}

In a Class III individual, the nasomaxillary complex may be retrusive, the mandible may be protrusive, or there could be a combination of both. Many years ago, the Class III malocclusion was viewed as a problem of the mandible. Until the 1960's and 70's the terms Class III and mandibular prognathism were basically synonymous. Although maxillary protraction using facemask therapy was first described more than a century ago, practitioners did not begin using it with frequency until the 1960 's. ${ }^{5}$ In 1997 Lee KG et al. stated that in 42- 
$62 \%$ of skeletal Class III malocclusions, a combination of a retrognathic maxilla and a normal to mildly prognathic mandible exists. ${ }^{32}$ Other combinations can exist as well including: Maxilla within normal range and mandibular prognathism, the maxilla and mandible are both prognathic and the mandible is prognathic and the maxilla is retrognathic.

Patients with a Class III malocclusion usually present with a concave facial profile. A maxillary deficiency can affect the entire midface causing the areas such as the zygomatic processes and nasal bridge to appear deficient. The tip of the chin, as well as the lower lip, will lie somewhere in front of a vertical line drawn from nasion, perpendicular to the Frankfort horizontal plane. A small maxilla will affect the craniofacial complex in a sagittal dimension as well causing a skeletally derived posterior dental crossbite. There is also often and increased lower facial height due to the maxilla not growing downward and forward.

Patients with class III malocclusions may present with varying combinations of skeletal, dental, and soft tissue combinations. The most common skeletal features include an obtuse gonial angle, a shortened anterior cranial base, a sagittal discrepancy of the maxilla or mandible, and an increased lower facial height. Dental findings usually include Angle Class III molars and canines with retroclined mandibular incisors and proclined maxillary incisors. This can result in an edge to edge incisor relationship or an anterior crossbite. In profile, the soft tissue outline appears concave. The nasolabial process is often acute with a retrusive upper lip and lower lip posturing forward.

With many different presentations and variations of a Class III skeletal and dental pattern, many question the underlying cause of this malocclusion. Understanding Class III 
growth trends is needed for effective treatment planning and for knowing the stability of treatment outcomes. This can help orthodontists when deciding between an orthodontic and surgical approach to treating this malocclusion. Longitudinal data on Class III subjects indicate that the rate of maxillary growth in Class III malocclusion during developmental ages is lower than expected for normal subjects being less than $1 \mathrm{~mm}$ per year. Also, mandibular growth is 3 to $4.5 \mathrm{~mm}$ per year. ${ }^{3}$ Miyajima et al studied Japanese female subjects and concluded that the maxilla exhibited a retrusive position at an early developmental stage and retained a fairly constant anteroposterior relationship to the cranial base structures with continued development. ${ }^{33}$ The mandible was protrusive early in development and became increasingly prognathic with age. ${ }^{34} \mathrm{~A}$ cross-sectional study by Battagel showed that the largest increments of mandibular length in male subjects occurred at ages of 15 years and older, indicating peak growth at a late age period. ${ }^{35}$ The female samples showed that the maximum changes in facial characteristics occurred between the ages of 11 and 12 years, but continued after 15 years of age. The control group for the females showed that facial growth had stopped at the age group of 14 to 17 years, but development remained active in the Class III group. ${ }^{5}$ Data suggests that growth trends in Class III malocclusions might be different from normal developmental patterns because peak growth occurs later and at relatively high rates until young adulthood. ${ }^{5}$ Adding to the data of this growth time and rate, a study conducted by Baccetti et al discovered that the duration of the peak interval of growth is approximately 6 months longer in Class III patients of both sexes than in those with normal occlusion. ${ }^{5}$

The average increase in Co-Gn for a Class I patient is 2 to $3 \mathrm{~mm}$. It is much greater in Class III subjects. Baccetti et al found that mandibular length increased between 6 and $7 \mathrm{~mm}$ 
for males and 4 to $5.5 \mathrm{~mm}$ in females in the same skeletal age group measured by patients' CVM. A similar amount of increase was also found by Miyajima et al in his female Class III subjects. $^{5,33}$ He also found that the maxilla showed a retrusive position at an early developmental stage and retained this anteroposterior position, whereas the mandibular position worsened with growth. ${ }^{33}$ There are important clinical implications with these findings that should be taken into account when treatment planning. With a much longer period of mandibular growth and the absence of growth by the maxilla, the timing for Orthognathic surgery should be carefully considered.

\section{Diagnosis of Class III malocclusion}

Diagnosing the underlying cause of a Class III malocclusion can come with differing opinions. In many areas of orthodontics, clinical preference or judgment can play a role. However, in order to differentiate the underlying cause of a Class III malocclusion, a simplified method of evaluating patients must be utilized. The following recommendations have been made in the assessment of Class III patients. ${ }^{36-38}$

The first step is to take a thorough family history. As mentioned, skeletal relationships are strongly hereditary and if a close relative required orthognathic surgery to correct a malocclusion, then this should alert the clinician that the patient may exhibit a potential skeletal discrepancy. Some Class III individuals can have a differing growth pattern compared to norms which presents as excessive late mandibular growth. This occurs most frequently in 
males during their late teens. Clinicians must be aware of this during the exam because a patient who presents with a less severe Class III skeletal pattern may not stay that way due to further growth potential.

Second, it is necessary to diagnose the presence of a functional shift or $\mathrm{CR} / \mathrm{CO}$ discrepancy. An anterior posturing of the mandible may result when an abnormal contact encourages the mandible to shift forward. It is important to distinguish the true Class III malocclusion from a Pseudo-Class III malocclusion. A pseudo-class III patient is usually characterized by having a Class I skeletal pattern, normal facial profile, and Class I molar relation in centric relation, but possesses a Class III skeletal and dental pattern in centric occlusion. The elimination of a $\mathrm{CR} / \mathrm{CO}$ discrepancy should reveal whether the malocclusion is a Class I or a compensated Class III malocclusion.

Third, a cephalometric analysis provides a quantitative assessment of the severity of the Class III malocclusion. This radiograph is always taken in Centric Relation with the mandible seated in its most superior anterior position. A lateral cephalogram aids in determining the cause of the malocclusions; whatever the combination of skeletal disharmony it may be.

Finally, the clinical assessment of the patient is very important in diagnosis. The anteroposterior skeletal base relationship and the vertical facial proportions should be assessed while the patient is standing upright with a natural head position. Profile disharmonies should be recorded at this time. The transverse dimension should be assessed along with any facial and dental asymmetries. The clinical exam includes the TMJ, associated musculature, oral mucosa, and occlusion. The use of mounted orthodontic study models can be an adjunct to the clinical 
exam revealing incisor relationship, overjet, overbite, incisor inclination, arch alignment, midline discrepancies and occlusal disharmonies such as a cant of the maxilla. The development of a problem list from all acquired data assists in the planning of Class III treatment.

\section{Treatment of a Class III malocclusion}

\section{Non-growing patient}

In the past, most of the treatment of Class III malocclusion involved a combination of orthodontic and orthognathic surgical correction upon completion of active growth of the patient. If the skeletal discrepancy is large and surgery is not an option, then a fair amount of negative overjet may still persist after orthodontic treatment.

Orthodontic camouflage can be performed on the growing or non-growing patient. It usually involves the extraction of mandibular first premolars with or without the extraction of maxillary second premolars. This extraction pattern is done to camouflage a moderate skeletal discrepancy when orthopedic correction by growth is not possible or there is dental crowding which requires extractions to obtain space to align the teeth in the arch. Extracting in Class III individuals allows the orthodontist to reduce the amount of negative overjet and camouflage the skeletal discrepancy. When there is doubt about further skeletal growth, orthodontic camouflage should be deferred until the remaining skeletal growth has been complete. 
Orthognathic surgery is a treatment alternative that will most likely lead to an ideal relationship of the maxilla and mandible in severe malocclusions. However, it is very invasive and financially demanding. Class III malocclusions makes up a small percentage of the malocclusions in the United States, but they comprise a substantial percentage of patients

seeking orthognathic surgery in adults. ${ }^{39,40}$ Pre-surgical orthodontic treatment usually involves the fixed appliances to align the maxillary and mandibular arches, so that they will coordinate when the skeletal bases are positioned properly in surgery. Since there is equilibrium between hard and soft tissues, orthodontic decompensation is usually necessary to gain the correct axial inclination of the incisors.

\section{Growing patient}

There is a lot more freedom when treating a growing patient with a Class III malocclusion. These options include camouflage treatment and, more importantly, functional orthopedic appliances. The goal of orthopedic correction of skeletal Class III discrepancies is to control and/or redirect the growth of the mandible and maxilla. Some functional appliances focus on the mandible, some focus more on the maxilla. The different orthopedic appliances used in the correction of skeletal Class III malocclusions include the chin cup appliance, the Frankel III appliance, and the maxillary protraction appliance.

The chin cup appliance which represents one of the oldest orthopedic appliances used to treat a skeletal Class III malocclusion is rarely used today. This was used heavily in the past when Class III malocclusions were thought to originate solely due to mandibular prognathism. These appliances, in order to be successful, were worn throughout growth. This is one of the 
chin cups draw backs. Another reason for abandoning this treatment is because greater forces are required to achieve orthopedic effects. It requires 600 to 800 grams of force which can cause the patient to experience temporomandibular joint problems. The last reason for discontinuing the chin cup as a treatment of choice is that the positive effects of the chin cup therapy were often not maintained due to latent mandibular growth.

The Frankel III appliance or FR-3 utilizes the maxillary and mandibular vestibules in the treatment of Class III malocclusions. The appliance shields the maxilla from the negative influence of the surrounding soft tissue, which in turn provides a restrictive force on the mandible. ${ }^{41}$ Treatment time with the FR-3 can be extensive; up to 24 months for a good result. The treatment effects include a forward maxillary movement, forward movement of the maxillary dentition, mandibular growth modification downward and backward, and lingual tipping of the mandibular incisors. Most practitioners use an FR-3 appliance, if used at all, as a retainer after facemask therapy is complete.

Facemask therapy in conjunction with maxillary expansion is the orthopedic treatment of choice today. It is an effective method of treating skeletal Class III malocclusion with maxillary retognathism and/or mandibular prognathism. The facemask, popularized by Delaire, uses the chin and forehead for support. The orthopedic force of this appliance is utilized to protract the maxilla while the chin support serves to redirect mandibular growth. Midfacial orthopedic expansion has been recommended for use in conjunction with protraction forces on the maxilla because it supposedly disrupts the circummaxillary sutural system and presumably facilitates the orthopedic effect of the face mask. ${ }^{8}$ 
Therapy involves the assisted forward growth of the maxilla which is accomplished by utilizing elastics to connect a fixed appliance on the posterior teeth to an extraoral anchorage site. The elastics are secured near the maxillary canines to avoid bite opening. A downward force of 30 degrees to the occlusal plane provides the greatest translator displacement of the craniofacial complex along the force application line. ${ }^{42}$ Anterior displacement requires $600-800$ $\mathrm{g}$ of force per side. Treatment time varies among individuals, but the average treatment length is 9 months wearing the facemask for at least 12 - 14 hours per day.

\section{Treatment timing for a growing patient}

One problem that clinicians have with treating retrusive maxillas early with facemask therapy is that mandibular growth cannot be predicted. ${ }^{43}$ One way to predict excessive mandibular growth is to look at the patients' family. ${ }^{4}$ Early treatment in patients with mandibular excess is not advised because early treatment to correct the prognathism of the mandible does not result in normal growth thereafter. On the other hand, the window for treatment of a patient with maxillary deficiency is very narrow. Orthopedic treatment is best rendered before the onset of puberty.

Over the last 20 years, the use of rapid maxillary expansion with protraction facemask has gained popularity among clinicians. The treatment effects are a combination of skeletal and dental modifications in both the maxilla and mandible. Optimal time to treat a child has been based primarily on clinical impressions with the suggested time between the ages of 6 and 
8 years. Treating at this early age is reported to remove factors that inhibit growth and development, such as an anterior crossbite that limits normal alveolar bone growth. Many investigators have conducted cephalometric studies of children treated with RME/FM to determine whether biologic indicators such as chronological age, stage of dental development, or skeletal age impact the orthopedic effects of treatment and future growth. ${ }^{12}$ Saadia et. al. found that younger patients show greater, faster results in less time under facemask therapy with the best results coming from the age group of 3 to 6 years. At this early age, compliance is improved and psychosocial scars which have been shown to affect patients into adulthood are reduced due to the patients' enhanced esthetics after treatment. ${ }^{44}$ Another study by Kapust and Turley found that the best age range for facemask therapy was between the ages of 4 and 7 years. $^{45}$ The 4 to 7 year age group showed statistically greater increases in the SNA angle. It was almost twice the change in SNA as the older group from 10 to 14 years. Baccetti et al showed that early treatment groups showed significantly greater advancement of maxillary structures and significantly more upward and forward direction of condylar growth after treatment. $^{5}$

Franchi et al investigated treatment timing for RME/FM based on an early treated group (ETG) if they were either in the deciduous or early mixed dentition, and late treated group (LTG) if they were in the late mixed dentition with erupting permanent canines and premolars. The results showed a significant differential between the groups of $7 \mathrm{~mm}$. The early treated patients maintained a maxillary/mandibular skeletal relationship within $1 \mathrm{~mm}$ because of the significant favorable skeletal contributions of the maxilla and the mandible. The maxilla showed a forward movement of $1.8 \mathrm{~mm}$ and the mandible expressed a significantly smaller 
anterior projection of $5 \mathrm{~mm}$ compared with the untreated Class III control. In the LTG, the skeletal movements could not achieve a positive change. The mandible moved forward more than the maxilla in the LTG and control group. However, treatment in the late mixed dentition produced significantly smaller increased in total mandibular length with respect to the control. A significant advancement of the maxilla can be achieved orthopedically only by treating Class III patients in the deciduous or early mixed dentition phases. About $2 \mathrm{~mm}$ of supplementary forward movement of the maxilla are maintained in treated patients at the completion of growth when compared with untreated subjects. This movement is not possible in the patients of late mixed dentition or older. In early developmental phases, mandibular growth control is associated with a significant decrease of the gonial angle in patients treated with RME/FM therapy. ${ }^{12}$ Because Franchi et al compared his treated group to a control group who also had Class III malocclusions, this allowed them to investigate the craniofacial growth characteristic for this type of skeletal discrepancy. The observations made in both the early and late control groups suggest that the skeletal imbalance in Class III malocclusion is established early in life and is not self-correcting during development. ${ }^{12}$ These investigators recommend early intervention for Class III malocclusion although patients treated during the late mixed dentition can still benefit from RME/FM therapy, but to a lesser degree.

Some of the rationales for early treatment of Class III Malocclusions include:

1. To prevent progressive irreversible soft tissue or bony changes. If the patient has an uncorrected anterior crossbite, it may lead to abnormal wear of incisors 
and dental compensation of incisors. Also, expansion in the permanent dentition can lead to histological changes in the pulp.

2. To improve skeletal discrepancies and provide a more favorable environment for future growth. This can minimize dental compensations such as overclosure of the mandible and over retraction of the lower incisors.

3. To improve occlusal function. A class III malocclusion is often accompanied by a functional shift. Elimination of a functional shift with orthopedic treatment may help the patient avoid adverse growth potential.

4. To simplify Phase II treatment. Early orthodontic or orthopedic treatment for mild of moderate Class III patients may eliminate the need for surgery. If the patient needs surgery, early treatment may minimize the extent of the surgery.

5. To provide more pleasing facial esthetics which can improve the psychosocial development of the child. Early treatment can improve lip posture and facial appearance.2

Each case must be considered individually. Factors that determine treatment may include familial history of a prognathic mandible or patient's age. Overcorrection is recommended because these patients tend to grow similarly to untreated Class III patients after facemask treatment. Currently there is a lack of long-term data to answer the many questions that continue to plague orthodontists in regard to long-term stability of facemask therapy. ${ }^{45}$ 


\section{Chapter III: Materials and Methods}

\section{Experimental Design and Methods}

The study group was composed of 76 consecutively patients treated with protraction facemask at a very early age using the Modified Hyrax Appliance. Due to exclusion criteria, the sample size was reduced to 23 patients. The pre-treatment craniofacial morphology had an average SNA measurement of 80, SNB of 81 , ANB of -0.3 , and Wits of -4.2 Patients were excluded if radiographs were not taken at each time point and if the radiographs were not of sufficient quality. All patients had lateral cephalometric radiographs taken pre-treatment (T1), post-treatment (T2), and an average of 22 months after removal of the appliance (T3). The mean age at the start of treatment was 6 years 2 months. The stage of dental development varied from primary dentition to early mixed dentition. The youngest age was 4 years 4 months and the oldest age was 10 years 4 months. The treatment time for each time point can be found in a table located in Appendix A. The average treatment time for T2-T1 was 9 months. Treatment time varied between 3 months to 16 months. All films were traced by a single investigator and compared using a customized cephalometric analysis, as described by Bjork ${ }^{21}$ and Pancherz. ${ }^{22}$

The Cervical Vertebra Maturation (CVM) for all subjects was an average of CVM 1.0. T1, $\mathrm{T} 2$, and $\mathrm{T} 3$ radiographs were all taken before pubertal growth had occurred. Therefore the treatment group was pooled together for analysis. 


\section{IRB Approval}

IRB exemption was obtained from West Virginia University prior to beginning this study.

\section{Cephalometric Analysis}

Lateral cephalograms were obtained from the office of Dr. Keibach. The time points obtained were Pre-treatment (T1), Post-Treatment (T2), and 22 month after appliance removal (T3). The radiographs were scanned and placed on a CD and mailed to the school. The files were downloaded in jpeg format, and digitized in Dolphin Imaging (Dolphin Imaging, Chatsworth, CA) to adjust for magnification. Each image was then printed 1:1 to ensure there was no magnification. The files were printed on an Epson Stylus Pro 3880 Printer on quality photo paper (HP Premium Photo Paper).

All landmarks and tracings were made on the printouts while viewing the original digital file. Tracings were performed by one operator using a $0.5 \mathrm{~mm}$ mechanical lead pencil, and orthodontic protractor, and 0.003 inch matte cephalometric acetate tracing film (3M Unitek, Monrovia, CA). A custom cephalometric analysis was performed as described by Bjork ${ }^{21}$ and Pancherz. $^{22}$ 
TABLE 1: Skeletal and Dental Landmarks

\begin{tabular}{|c|c|c|}
\hline Name & Symbol & Definition \\
\hline Sella & $\mathrm{S}$ & The center of the sella turcica \\
\hline Nasion & $\mathrm{N}$ & The most anterior point of the nasofrontal suture \\
\hline Anterior Nasal Spine & ANS & The apex of the spina nasalis anterior \\
\hline Posterior Nasal Spine & PNS & $\begin{array}{l}\text { The most posterior point on contour of the palate in the } \\
\text { midsagittal plane }\end{array}$ \\
\hline Subspinale & A pt. & $\begin{array}{l}\text { The deepest point in the concavity of the anterior maxilla } \\
\text { between the ANS and the alveolar crest }\end{array}$ \\
\hline Supramentale & B pt. & $\begin{array}{l}\text { The deepest point in the concavity of the anterior mandible } \\
\text { between the alveolar crest and pogonion }\end{array}$ \\
\hline Pogonion & $\mathrm{Pg}$ & The most prominent point on the chin \\
\hline Menton & $\mathrm{Me}$ & The deepest point of the mandibular symphysis \\
\hline Gonion & Go & $\begin{array}{l}\text { The lowest point of the bony contour of the angle of the } \\
\text { mandible }\end{array}$ \\
\hline $\begin{array}{l}\text { Maxillary incisor } \\
\text { apex }\end{array}$ & Isa & The root apex of the most prominent maxillary central incisor \\
\hline Maxillary incisor & Is & $\begin{array}{l}\text { The incisal point of the most prominent maxillary central } \\
\text { incisor }\end{array}$ \\
\hline $\begin{array}{l}\text { Mandibular incisor } \\
\text { apex }\end{array}$ & lia & $\begin{array}{l}\text { The root apex of the most prominent mandibular central } \\
\text { incisor }\end{array}$ \\
\hline Mandibular incisor & li & $\begin{array}{l}\text { The incisal point of the most prominent mandibular central } \\
\text { incisor }\end{array}$ \\
\hline $\begin{array}{l}\text { Molar superius } \\
\text { mesial cusp }\end{array}$ & Msc & $\begin{array}{l}\text { The mesio-buccal cusp tip of the maxillary first permanent } \\
\text { molar }\end{array}$ \\
\hline Molar Superius & Ms & $\begin{array}{l}\text { The mesial contact point of the maxillary permanent first } \\
\text { molar }\end{array}$ \\
\hline $\begin{array}{l}\text { Molar inferius mesial } \\
\text { cusp }\end{array}$ & Mic & $\begin{array}{l}\text { The mesial-buccal cusp tip of the mandibular first permanent } \\
\text { molar }\end{array}$ \\
\hline Molar inferius & Mi & $\begin{array}{l}\text { The mesial contact point of the mandibular first permanent } \\
\text { molar }\end{array}$ \\
\hline
\end{tabular}


Figure 1: Skeletal and Dental Landmarks

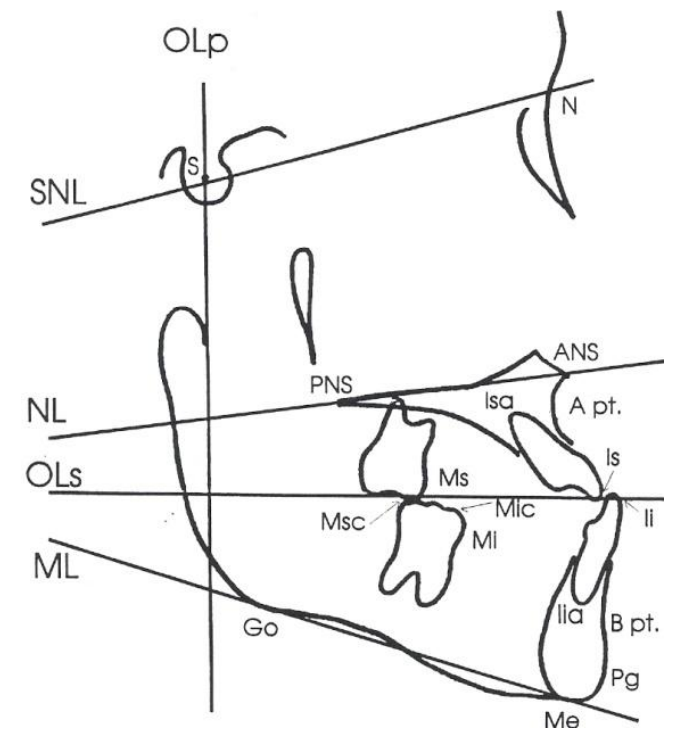

Table 2: Definition of Reference Lines

\begin{tabular}{|l|l|l|}
\hline Name & Symbol & Definition \\
\hline Sella-Nasion plane & SNL & Reference line joining Nasion and Sella \\
\hline Maxillary plane & NL & $\begin{array}{l}\text { Reference line joining anterior nasal spine and posterior } \\
\text { nasal spine }\end{array}$ \\
\hline Occlusal plane & OL & $\begin{array}{l}\text { Reference line joining maxillary incisal edge and the molar } \\
\text { superious mesial cusp tip }\end{array}$ \\
\hline Mandibular plane & ML & Refernce line joining menton and gonion \\
\hline $\begin{array}{l}\text { Occlusal plane } \\
\text { perpendicular }\end{array}$ & OLp & $\begin{array}{l}\text { Reference line produced by dropping a perpendicular line } \\
\text { from sella to the occlusal plane }\end{array}$ \\
\hline
\end{tabular}




\section{Sagittal Measurements}

Figure 2. The reference grid (OLs and OLp) and measuring points used in the sagittal cephalometric analysis.

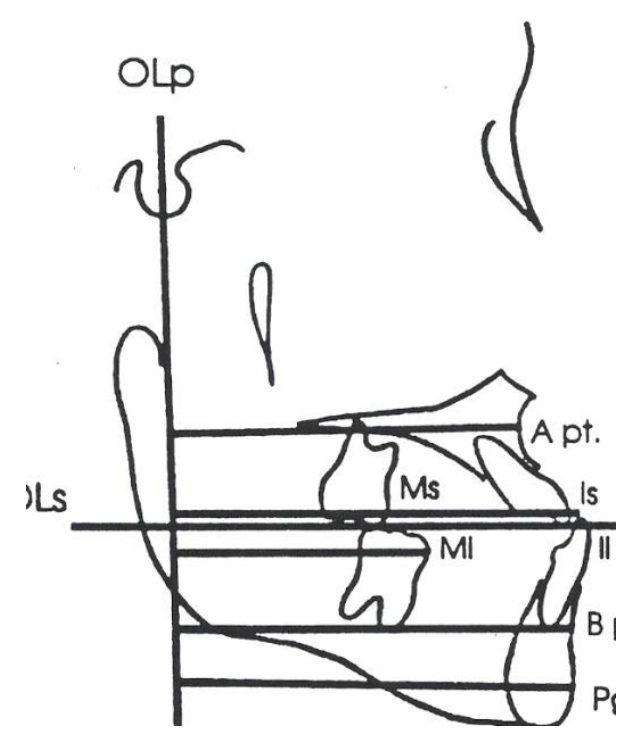

Skeletal and dental changes in A-point, Is, Ms, li, Mi, and Pogonion compared to OLs and OLp were measured by forming a reference grid based on the occlusal line (OLs) and occlusal line perpendicular (OLp) see Figure 2. The reference grid was traced on T1 and used for all sagittal measurements between OLp and the cephalometric landmarks transferring the grid by superimposition from T1 to T2 and T3. Sagittal measurments taken can be seen in Table 3. The measurement for each sagittal measurement was performed with an electronic digital caliper and measured to the nearest $0.1 \mathrm{~mm}$. The caliper was calibrated to $0.0 \mathrm{~mm}$ prior to each measurement. Lateral cephalograms often present landmarks with right and left images; therefore, the midpoint bisecting the two images was used. 
Table 3: Sagittal Measurements of variables 1-9

\begin{tabular}{|l|l|}
\hline Variable (mm) & Definition \\
\hline Skeletal Measuring Points: & \\
\hline 1. OLp-A & Position of maxillary base \\
\hline 2. OLp-Pg & Position of mandibular chin \\
\hline 3. Wits & Mx and Md position relative to OLs \\
\hline Dental Measuring Points: & \\
\hline 4. Is/OLp & Position of maxillary central incisor \\
\hline 5. li/OLp & Position of mandibular central incisor \\
\hline 6. Overjet & Is/OLp minus li/OLp \\
\hline 7. Ms/OLp & Position of maxillary first permanent molar \\
\hline 8. Mi/OLp & Position of Mandibular first permanent molar \\
\hline 9. Molar rel. & Molar relationship: Ms/OLp minus Mi/OLp \\
\hline
\end{tabular}

\section{Vertical Measurements}

Vertical measurements used OLs, NL, and ML. A measurement from Nasion to a-point and ANS to Me was also included. Measurements from T1, T2, and T3 were not superimposed. The equipment and measurement protocol was exactly the same as used in the Sagittal Measurement mentioned above. Vertical measurements can be seen in Figure 3 and Table 4. 
Figure 3: The reference lines and measuring points used in the vertical cephalometric analysis.

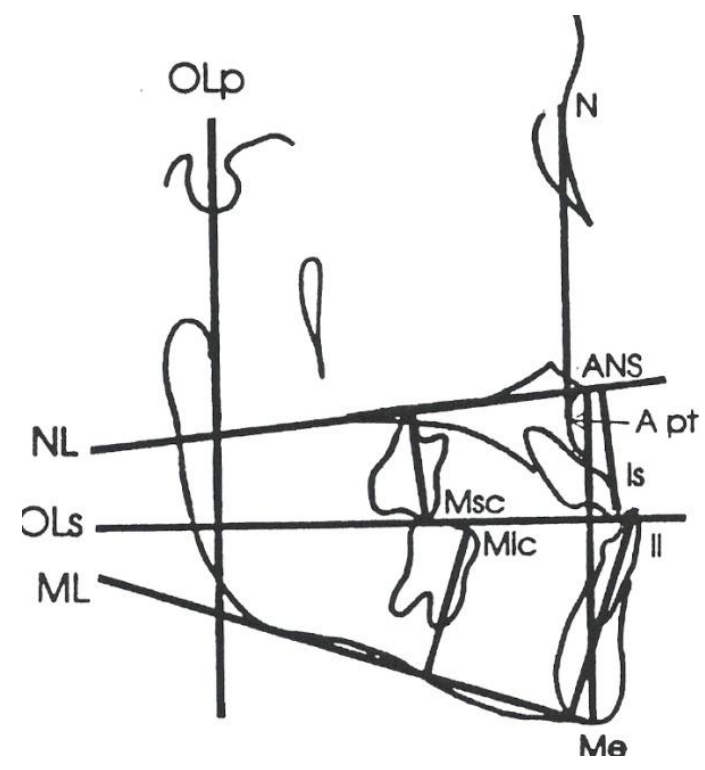

Table 4: Vertical Measurments of variables 10-16

\begin{tabular}{|c|c|}
\hline Variable $(\mathrm{mm})$ & Definition \\
\hline \multicolumn{2}{|l|}{ Skeletal measuring points: } \\
\hline 10. $\mathrm{N}-\mathrm{A} \mathrm{pt}$. & Maxillarv vertical positioning \\
\hline 11. ANS-Me & Lower facial height \\
\hline \multicolumn{2}{|l|}{ Dental measuring points: } \\
\hline 12. Is-NL & 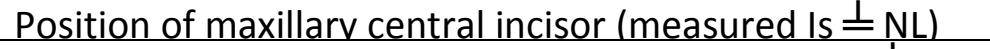 \\
\hline 13. Ii-ML & Position of mandibular central incisor (measured $\mathrm{li} \perp \mathrm{ML}$ ) \\
\hline 14. Overbite & Distance form li $\perp$ OLs \\
\hline 15. $\mathrm{Msc}-\mathrm{NL}$ & Position of maxillarv permanenet forst molar $(\mathrm{Msc} \perp \mathrm{NL})$ \\
\hline 16. Mic-ML & Position of mandibular permanent first molar (Mic $\perp \mathrm{ML})$ \\
\hline
\end{tabular}

\section{Angular Measurements}

Angular measurements were used in addition to the grid measurements in order to

identify changes in the dentofacial complex. These angular measurements are shown in Figure 4 below. Also, the angular measurements are defined in Table 5 below. The measurement for 
each angular variable was performed by using a cephalometric protractor and was measured to the nearest degree.

Figure 4: The reference lines and measuring points used for angular cephalometric analysis.

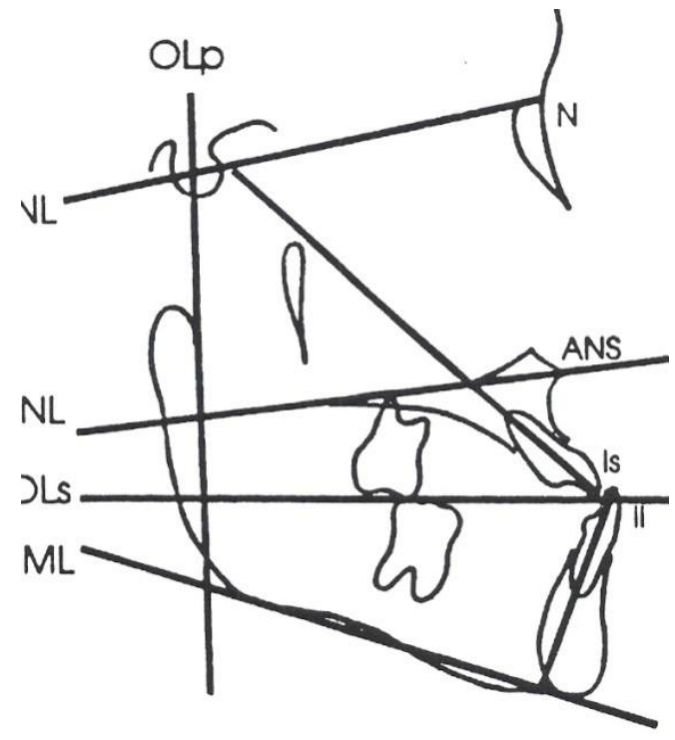


Table 5: Angular Measurements of variables 17-25

\begin{tabular}{|l|l|}
\hline Variable $\left(^{\circ}\right.$ ) & Definition \\
\hline Skeletal measuring points: & \\
\hline 17. SNA & Maxillary base relative to SNL \\
\hline 18. SNB & Mandibular base relative to SNL \\
\hline 19. ANB & SNA minus SNB \\
\hline 20. SNL-ML & Mandibular plane angle \\
\hline 21. SNL-OL & Occlusal plane angle \\
\hline 22. SNL-NL & Palatal plane angle \\
\hline Dental measuring points: & \\
\hline 23. Is/SNL & Maxillary central incisor angle \\
\hline 24. li/ML & Mandibular central incisor angle \\
\hline 25. Is/li & Interincisal angle \\
\hline
\end{tabular}

All lateral cephalograms were be calibrated to a 1:1 ratio using Dolphin software

(Dolphin Imaging, Chatsworth, CA). Data was analyzed with ANOVA and a multiple comparison t-test.

\section{Method Error}

The reliability of the cephalometric measurements was tested by evaluating the error in locating, superimposing, and measuring the differences in the landmarks. Pre-treatment (T1), Post-treatment (T2), and Follow up (T3) radiographs of 6 randomly selected patients were retraced two weeks after initial tracing and were analyzed to evaluate the error. For all cephalometric variables, differences between the measurements from the first and second 
tracings were compared for each individual at $\mathrm{T} 1, \mathrm{~T} 2$, and $\mathrm{T} 3$. A reliability coefficient was

established for each variable at each time point to determine the degree of reliability (Table 6).

Table 6: Reliability Coefficients for all variables at T1, T2, and T3

\begin{tabular}{|l|l|}
\hline Variables & Reliability \\
\hline Sagittal: & \\
\hline Olp-A & 0.98 \\
\hline Olp-Pg & 0.96 \\
\hline Is-Olp & 0.99 \\
\hline li-Olp & 0.98 \\
\hline Overjet & 0.88 \\
\hline Ms-Olp & 0.98 \\
\hline Mi-Olp & 0.95 \\
\hline Molar Relationship & 0.75 \\
\hline Vertical: & \\
\hline N-A & 0.95 \\
\hline ANS-Me & 0.96 \\
\hline Is-NL & 0.97 \\
\hline li-ML & 0.95 \\
\hline Overbite & 0.91 \\
\hline Msc-NL & 0.97 \\
\hline Mic-ML & 0.96 \\
\hline Angular: & \\
\hline SNA & 0.80 \\
\hline SNB & 0.92 \\
\hline ANB & 0.88 \\
\hline SNL-NL & 0.93 \\
\hline SNL-ML & 0.94 \\
\hline SNL-OLs & 0.95 \\
\hline Is/SNL & 0.97 \\
\hline li/ML & 0.97 \\
\hline Is/li & 0.97 \\
\hline
\end{tabular}


The method of cephalometric analysis used in this study was determined to be reliable.

This included the identification of landmarks, superimposition of radiographs, and the measurements taken at each time point. Reliability ranged from 0.75 to 0.99 , which means that the method of data collection was reliable.

\section{Evaluation of Overjet and Molar Relationship Correction}

To determine the amount of skeletal and dental contribution to the overjet and molar relationship correction, the amount of dental change in the maxilla and mandible was calculated. The method of obtaining these measurements is shown below (Table 7).

Table 7: Calculation of Overjet and Molar Relationship Changes

\begin{tabular}{|l|l|}
\hline \multicolumn{1}{|c|}{ Overiet } & \multicolumn{1}{c|}{ Molar Relationship } \\
\hline $\begin{array}{l}\text { Skeletal contributions: } \\
\text { 1. OLp-Apt }\end{array}$ & Skeletal contributions: \\
2. OLP-Pg & 1. OLp-Apt \\
& 2. OLP-Pg \\
Dental contributions: & Dental contributions: \\
3. Is-OLp minus OLp-Apt & 3. Ms-OLp minus OLp-Apt \\
4. li-OLp minus OLp-Pg & 4. Mi-OLp minus OLp-Pg \\
Overjet correction: & Molar relationship correction: \\
Sum of 1,2,3,and 4 & Sum of 1,2,3,and 4 \\
\hline
\end{tabular}


When adding figures from the above table, the following formula was used for overjet correction:

Overjet Correction $=$ Maxilla + Mx incisor - Mandible - Md incisor

Maxilla $=$ OLp-A pt

Mx incisor $=I s-O L p$ minus OLp-A pt.

Mandible $=\mathrm{OLp}-\mathrm{Pg}$

Mandibular incisor $=\mathrm{li}-\mathrm{OLp}$ minus OLP-Pg

When adding figures from the above table, the following formula was used for molar relationship correction or increase:

Molar Relationship Correction $=$ Maxilla + Mx Molar - Mandible - Md Molar

Maxilla $=$ OLp-A pt

Maxillary molar $=$ Ms-OLp minus OLp-A pt.

Mandible $=\mathrm{OLp}-\mathrm{Pg}$

Mandibular molar $=$ Mi-OLp minus OLp-Pg 


\section{Statistical Analysis}

A paired t-test was used to compare $\mathrm{T} 1$ to $\mathrm{T} 2, \mathrm{~T} 2$ to $\mathrm{T} 3$, and $\mathrm{T} 1$ to $\mathrm{T} 3$. This was used on each variable to identify the overall treatment effects of the Modified Hyrax Expander in combination with protraction facemask treatment. A level of significance of $p<0.05$ (95\% confidence interval) was used in this study.

In order to obtain the coefficient of reliability a measurement was made on the initial tracing and another measurement was made on the same tracing 2 weeks later. When there are two measurements, the coefficient of reliability is the correlation coefficient of the first and second measurements. This information is found on Table 6 . Correlation coefficients were reported to determine how strongly the first measurements were associated with the second measurements of each variable at every time period in six individuals. 


\section{Chapter IV: Results}

\section{Cephalometric Measurements}

The measurements for each of the 25 variables were analyzed. The mean, standard deviation, maximum and minimum for each variable measurement were recorded for each time period (T1, T2, and T3). Table 8 shows the sagittal, vertical and angular measurements at time periods $\mathrm{T} 1, \mathrm{~T} 2$, and $\mathrm{T} 3$. 
Table 8: Cephalometric Measurements

\begin{tabular}{|c|c|c|c|c|c|c|c|c|c|c|c|c|}
\hline \multirow[b]{2}{*}{ Variable } & \multicolumn{4}{|c|}{ T1 } & \multicolumn{4}{|c|}{$\mathrm{T} 2$} & \multicolumn{4}{|c|}{ T3 } \\
\hline & Mean & S.D. & Min & Max & Mean & S.D. & Min & Max & Mean & S.D. & Min & Max \\
\hline \multicolumn{13}{|l|}{ Sagittal: } \\
\hline Olp-A pt. & 63.81 & 4.79 & 56.5 & 74.45 & 66.45 & 4.86 & 59.17 & 79.5 & 68.00 & 5.13 & 60 & 78.9 \\
\hline Olp-Pg & 67.79 & 5.51 & 59.6 & 79.33 & 68.46 & 6.28 & 58.75 & 82.5 & 72.20 & 6.64 & 59.1 & 89.8 \\
\hline Is-Olp & 66.54 & 6.46 & 58.5 & 83.98 & 70.34 & 7.12 & 61 & 90.68 & 73.68 & 7.77 & 58.78 & 90.92 \\
\hline li-Olp & 68.45 & 6.52 & 60.22 & 86.55 & 68.12 & 6.89 & 58.68 & 86.9 & 71.79 & 6.67 & 61.2 & 86.47 \\
\hline Overjet & -1.90 & 1.33 & \begin{tabular}{|l|}
-4.37 \\
\end{tabular} & 2.2 & 2.22 & 1.40 & -.95 & 5.1 & 1.93 & 1.89 & -2.42 & 4.45 \\
\hline Ms-Olp & 39.15 & 5.51 & 32 & 51.58 & 42.10 & 4.59 & 35.62 & 53.3 & 44.96 & 5.70 & 36 & 56.26 \\
\hline Mi-Olp & 41.59 & 5.25 & 34.27 & 55.05 & 42.83 & 5.16 & 36.84 & 54.3 & 45.92 & 5.72 & 38 & 58.26 \\
\hline Molar Relationship & -2.39 & 1.49 & -5.05 & 0.6 & -0.72 & 2.23 & -5.75 & 3.8 & -0.96 & 1.79 & -4.56 & 3.5 \\
\hline Wits & -4.2 & 1.9 & -8.4 & 0.0 & -1.0 & 2.9 & -7.1 & 4.4 & -2.5 & 2.0 & -6.8 & 1.7 \\
\hline \multicolumn{13}{|l|}{ Vertical: } \\
\hline Nasion-Apt & 44.18 & 3.14 & 40.53 & 50.8 & 46.55 & 3.60 & 41 & 56.26 & 49.86 & 3.69 & 42.8 & 60 \\
\hline ANS-Me & 52.87 & 4.56 & 44.75 & 63.67 & 56.08 & 5.96 & 46.71 & 70.23 & 56.85 & 5.61 & 46.85 & 68.23 \\
\hline Is-NL & 22.26 & 3.27 & 17.61 & 31.32 & 23.59 & 4.06 & 18.23 & 35.4 & 24.61 & 3.91 & 18.73 & 33.59 \\
\hline Ii-ML & 33.07 & 3.22 & 28.74 & 41.64 & 34.37 & 3.70 & 29.13 & 44.37 & 35.81 & 3.56 & 29.09 & 44.55 \\
\hline Overbite & 1.98 & 1.61 & -1.57 & 4.31 & 1.02 & 1.39 & -2.2 & 2.95 & 1.42 & 1.70 & -1.2 & 4.11 \\
\hline Msc-NL & 14.11 & 2.25 & 10.86 & 19.4 & 15.61 & 2.81 & 12.3 & 24.6 & 16.12 & 2.79 & 11.12 & 23.56 \\
\hline Mic-ML & 21.75 & 2.59 & 18.94 & 30.43 & 22.75 & 2.86 & 18.2 & 30.33 & 24.02 & 2.79 & 19.63 & 31.55 \\
\hline \multicolumn{13}{|l|}{ Angular: } \\
\hline SNA & 80.39 & 4.33 & 70 & 90 & 80.78 & 3.86 & 75 & 86 & 80.17 & 3.96 & 74 & 87 \\
\hline SNB & 80.56 & 4.28 & 72 & 91 & 78.82 & 3.98 & 70 & 85 & 79.30 & 3.37 & 72 & 85 \\
\hline ANB & -0.26 & 2.24 & -4 & 6 & 1.91 & 2.06 & -3 & 5 & 0.73 & 2.61 & -4 & 9 \\
\hline SNL-NL & 7.30 & 3.92 & 1 & 17 & 7.39 & 3.61 & 3 & 16 & 8.04 & 3.72 & 2 & 18 \\
\hline SNL-ML & 32.08 & 3.67 & 26 & 39 & 33.04 & 4.18 & 25 & 42 & 31.26 & 4.35 & 25 & 39 \\
\hline SNL-Ols & 15.78 & 4.26 & 9 & 24 & 16.04 & 3.58 & 9 & 25 & 15.95 & 3.94 & 9 & 23 \\
\hline Is/NL & 93.60 & 9.28 & 80 & 113 & 96.95 & 8.48 & 85 & 113 & 103.43 & 9.35 & 88 & 120 \\
\hline li/ML & 87.13 & 6.67 & 82 & 106 & 85.21 & 7.61 & 71 & 102 & 90.39 & 10.12 & 74 & 115 \\
\hline Interincisal Angle & 148.08 & 10.22 & 120 & 159 & 145.87 & 13.50 & 120 & 170 & 136 & 12.81 & 117 & 161 \\
\hline
\end{tabular}




\section{Cephalometric Changes of T2-T1, T3-T2, and T3-T1}

Changes of cephalometric measurements in patients treated with protraction headgear before treatment (T1), after treatment (T2) and 22 months after removal of the appliance (T3) are shown in Table 9. Of the 25 variables investigated significant changes were found in most of the variables.

Figures 5, 6, and 7 summarize the changes during treatment for T2-T1. Overjet and sagittal molar relationships improved by an average of $4.1 \mathrm{~mm}$ and $1.8 \mathrm{~mm}$, respectively. Looking at Table 9, 7 out of 9 sagittal measurements were significant. The non-significant measurements were OLp-Pg and Ii-OLp. This means that Pogonion did not have a significant change between time points T2 and T1. The lower incisor inclination was also non-significant. Vertical changes included an overbite decrease of $0.96 \mathrm{~mm}$. This decrease in overbite was due to primary teeth being exfoliated and permanent central incisors erupting during treatment. It could also have been due to the Stainless Steel Crown used in the Modified Hyrax Expander. As the patients wore the facemask, the maxilla grew downward and forward while the mandible grew vertically as well. Only four out of the nine measurements for the Angular section were statistically significant. The four that were statistically significant were: $S N B, A N B$, Is/SNL, and li/ML. This shows that the mandibular prominence changed significantly between T2 and T1 measurements. Also, the maxillary incisor angulation changed significantly. Measurements that were not statistically significant were SNA, SNL-NL, SNL-ML, SNL-OLs, and Is/li. A-point has variability upon location and the palatal plane, occlusal plane, and mandibular plane did not 
change significantly between T2 and T1. Also, the interincisal angle did not change significantly during protraction facemask treatment.

Figures 8,9 , and 10 show the cephalometric changes 22 months after appliance removal (T3-T2). Significant differences were found in 16 of the 24 variables. Over approximately 2 years, the maxilla continued to move forward by $1.5 \mathrm{~mm}$, while the mandible moved forward $3.7 \mathrm{~mm}$. Most of the overjet and molar correction, therefore, can be attributed to dental movements. The mean overjet correction decreased by $0.3 \mathrm{~mm}$ and the mean molar correction decreased by $0.2 \mathrm{~mm}$. Wits decreased $1.4 \mathrm{~mm}$ showing skeletal relapse as well. There was a big difference between the Vertical group T2-T1 and T3-T2 (Table 9). In the T2-T1 group, all of the variables were statistically significant; however, only 4 out of 7 of the variables were statistically significant for the T3-T2 group. The non-significant findings were ANS-Me, Overbite, and Msc-NL. The overbite decreased an average of $0.40 \mathrm{~mm}$ and this was most likely due to the error mentioned above. Under the Angular group, 5 of the 9 values were statistically significant measurements (Table 9). They were ANB, SNL-ML, Is/SNL, li/ML, and Is/li. This shows that the incisors changed angulation significantly and the mandibular plane angle also changed significantly. This also shows that ANB had a significant change, but this change was a negative number meaning there was skeletal relapse. ANB decreased an average of 1.17 degrees during the 22 months after appliance removal.

Figure 11, 12, and 13 shows the net changes for 9 months of treatment and 22 months of observation (T3-T1). The maxilla moved forward $4.2 \mathrm{~mm}$ and the mandible moved forward $4.4 \mathrm{~mm}$. The maxillary incisor tipped labially $2.9 \mathrm{~mm}$ and the mandibular incisor tipped lingually 
$1.1 \mathrm{~mm}$, resulting in a net overjet correction of $3.8 \mathrm{~mm}$. Mesial movement of the maxillary molars was $1.6 \mathrm{~mm}$, while the mandibular molars moved distally and average of $0.1 \mathrm{~mm}$. A net improvement in molar relationship was $1.7 \mathrm{~mm}$, contributing to a $113 \%$ overall dental correction for the mandibular molars. Most of the values found in Table 9 for T3-T1 were statistically significant. This shows there was a positive net change over the 9 months of treatment and 22 months of observation. Wits maintained a net correction of $1.6 \mathrm{~mm}$. The measurements that were not statistically significant are as follows: Overbite, SNA, SNL-NL, SNL$\mathrm{ML}$, and SNL-OLs. The overbite is most likely non-significant because the primary incisors on some patients could have exfoliated during treatment. This would have left the permanent incisors in the process of erupting throughout treatment. SNA was insignificant due to the difficulty in marking A point. The palatal plane, occlusal plane, and mandibular plane were not significant for T3-T1. SNL-ML, or mandibular plane, was the only planed measurement to have a significant finding at any time point measured in this study and it was between T3 and T2.

The values for T2-T1, T3-T2, and T3-T1 are listed below in Table 9. 
Table 9: Comparison of T2-T1, T3-T1, and T3-T2

\begin{tabular}{|c|c|c|c|c|c|c|c|c|c|c|c|c|}
\hline \multirow[t]{2}{*}{ Variables } & \multicolumn{4}{|c|}{ T2-T1 } & \multicolumn{4}{|c|}{ T3-T2 } & \multicolumn{4}{|c|}{ T3-T1 } \\
\hline & Mean & S.D & P val & sig & Mean & S.D. & $P$ val & sig & Mean & S.D. & P val & sig \\
\hline \multicolumn{13}{|l|}{ Sagittal: } \\
\hline Olp-A & 2.6 & 1.5 & .0001 & $*$ & 1.5 & 2.0 & .0014 & $*$ & 4.2 & 2.3 & .0001 & $*$ \\
\hline Olp-Pg & 0.6 & 2.7 & .2571 & NS & 3.7 & 3.6 & .0001 & $*$ & 4.4 & 4.4 & .0001 & $*$ \\
\hline Is-Olp & 3.8 & 2.4 & .0001 & $*$ & 3.3 & 3.1 & .0001 & $*$ & 7.1 & 4.1 & .0001 & $*$ \\
\hline li-Olp & -0.3 & 2.5 & .5371 & NS & 3.6 & 3.1 & .0001 & $*$ & 3.3 & 3.7 & .0003 & $*$ \\
\hline Overjet & 4.1 & 2.1 & .0001 & * & -0.3 & 1.7 & .4374 & NS & 3.8 & 2.4 & .0001 & $*$ \\
\hline Ms-Olp & 2.9 & 2.7 & .0001 & $*$ & 2.8 & 2.7 & .0001 & $*$ & 5.8 & 3.3 & .0001 & $*$ \\
\hline Mi-Olp & 1.2 & 2.1 & .0083 & $*$ & 3.1 & 3.2 & .0002 & $*$ & 4.3 & 3.5 & .0001 & $*$ \\
\hline Molar Rel & 1.6 & 2.0 & .0007 & $*$ & -0.2 & 1.6 & .4860 & NS & 1.4 & 1.7 & .0008 & $*$ \\
\hline Wits & 3.1 & 2.6 & .0001 & $*$ & 1.6 & 2.5 & .0049 & $*$ & -1.4 & 2.4 & .0121 & $*$ \\
\hline \multicolumn{13}{|l|}{ Vertical: } \\
\hline$N-A$ & 2.3 & 2.3 & .0001 & $*$ & 3.3 & 2.2 & .0001 & $*$ & 5.7 & 2.7 & .0001 & $*$ \\
\hline ANS-Me & 3.2 & 2.7 & .0001 & $*$ & 0.7 & 2.6 & .1733 & NS & 4.0 & 2.1 & .0001 & $*$ \\
\hline Is-NL & 1.3 & 1.5 & .0004 & $*$ & 1.0 & 2.0 & .0251 & $*$ & 2.3 & 2.0 & .0001 & $*$ \\
\hline li-ML & 1.3 & 1.2 & .0001 & $*$ & 1.4 & 1.2 & .0001 & $*$ & 2.7 & 1.1 & .0001 & $*$ \\
\hline Overbite & -0.9 & 1.7 & .0150 & * & 0.4 & 1.7 & .2548 & NS & -0.6 & 1.9 & .1659 & NS \\
\hline Msc-NL & 1.4 & 1.6 & .0002 & $*$ & 0.5 & 1.8 & .1886 & NS & 2.0 & 1.3 & .0001 & $*$ \\
\hline Mic-ML & 1.0 & 1.4 & .0035 & $*$ & 1.3 & 1.4 & .0003 & $*$ & 2.3 & 1.6 & .0001 & $*$ \\
\hline \multicolumn{13}{|l|}{ Angular: } \\
\hline SNA & 0.4 & 2.5 & .4671 & NS & -0.6 & 2.2 & .2002 & NS & -0.2 & 2.5 & .6833 & NS \\
\hline SNB & -1.7 & 2.4 & .0021 & $*$ & 0.4 & 1.7 & .1848 & NS & -1.2 & 2.4 & .0211 & $*$ \\
\hline ANB & 2.2 & 2.5 & .0004 & $*$ & -1.2 & 2.1 & .0155 & $*$ & 1 & 1.9 & .0184 & $*$ \\
\hline SNL-NL & 0.1 & 2.2 & .8549 & NS & 0.6 & 2.0 & .1388 & NS & 0.7 & 2.1 & .1012 & NS \\
\hline SNL-ML & 0.9 & 2.6 & .1020 & NS & -1.8 & 2.8 & .0068 & $*$ & -0.8 & 2.7 & .1551 & NS \\
\hline SNL-OLS & 0.3 & 3.2 & .7064 & NS & -0.1 & 3.6 & .9093 & NS & 0.2 & 4.3 & .8470 & NS \\
\hline Is/SNL & 3.3 & 5.9 & .0131 & $*$ & 6.5 & 6.3 & .0001 & $*$ & 9.8 & 8.7 & .0001 & $*$ \\
\hline li/ML & -1.9 & 4.2 & .0426 & $*$ & 5.2 & 6.1 & .0006 & $*$ & 3.2 & 7.4 & .0463 & $*$ \\
\hline Is/li & -2.2 & 8.8 & .2403 & NS & -9.8 & 8.2 & .0001 & $*$ & -12.1 & 10.8 & .0001 & $*$ \\
\hline
\end{tabular}




\section{Overjet and Molar Relationship Correction}

T2-T1:

\begin{tabular}{|cccc|}
\hline Overiet Correction: & & Molar relationship: & \\
Skeletal Contribution: & & Skeletal Contribution: & \\
1) Maxilla & 2.6 & 1) Maxilla & 2.6 \\
2) Mandible & 0.7 & 2) Mandible & 0.7 \\
Dental Contribution: & & Dental Contribution: & \\
3) Mx incisor & 1.2 & 3) Mx molar & 0.4 \\
4) Md incisor & -1.0 & 4) Md molar & 0.5 \\
\hline
\end{tabular}

Overjet Correction $=$ Maxilla + Mx incisor - Mandible - Md incisor

Overjet Correction $=2 \cdot 6+1 \cdot 2-0.7-(-1 \cdot 0)=4.1$

Figure 5: Components of Overjet Correction T2-T1

Overjet Correction
of $4.1 \mathrm{~mm}$

Skeletal contribution

$=1.9 \mathrm{~mm}$

Dental contribution

$=2.2 \mathrm{~mm}$
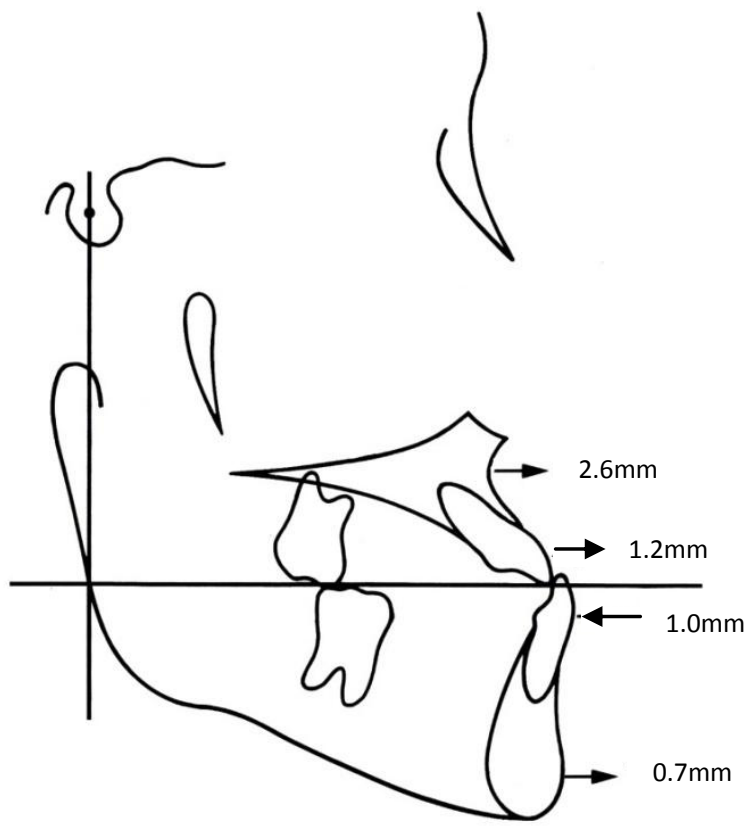
Molar Relationship Correction = Maxilla + Mx molar - Mandible - Md

Molar Relationship Correction $=2.6+.4-0.7-.5=1.8$

Figure 6: Components of Molar Correction T2-T1
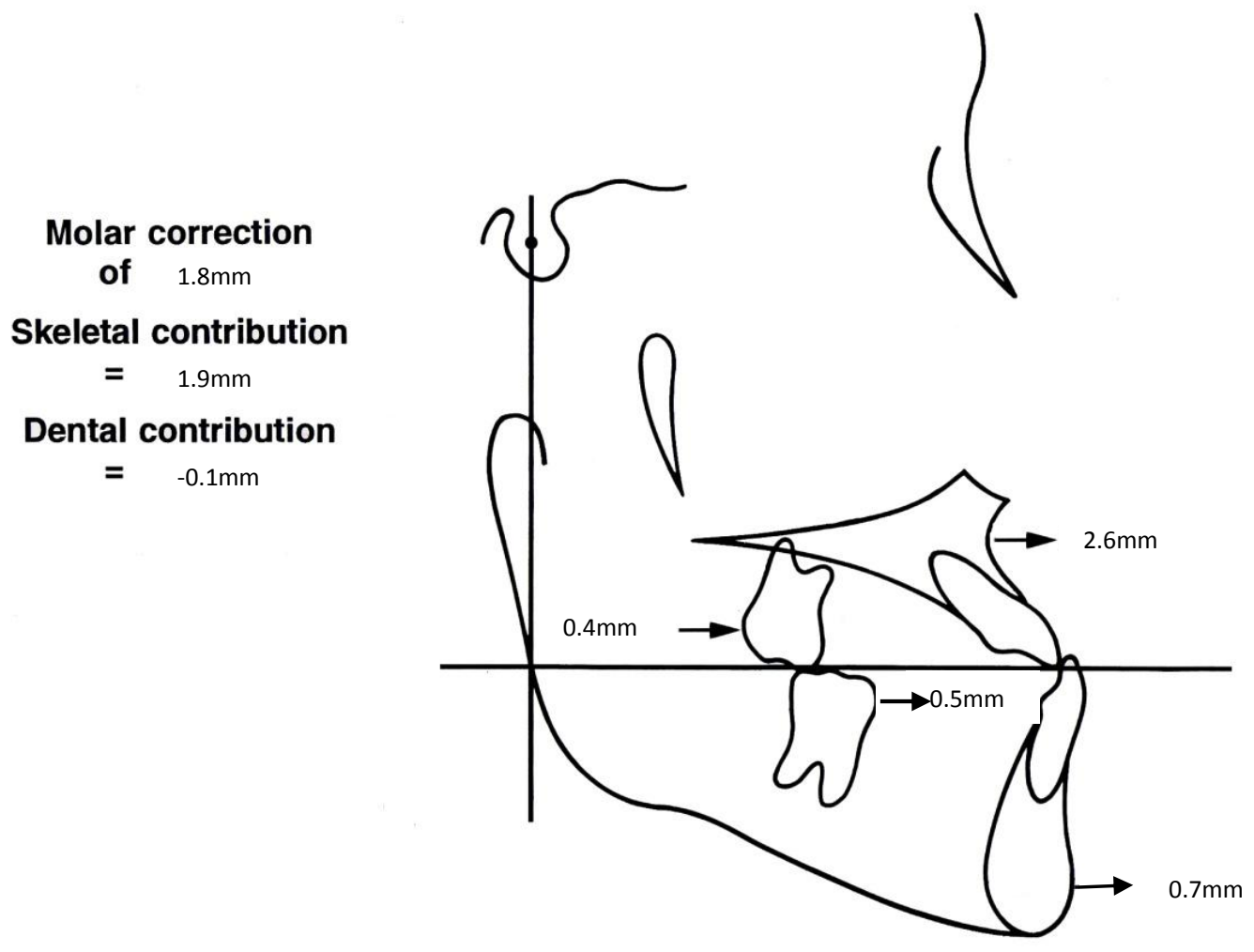
The amount of skeletal and dental contribution to the overjet and molar relationship correction for T2-T1 was calculated using the formulas in Table 7. The amount of overjet correction was $4.1 \mathrm{~mm}$. The amount of correction attributed to skeletal movement was $1.9 \mathrm{~mm}$ or $46 \%$ and the amount of dental correction was $2.2 \mathrm{~mm}$ or $54 \%$. The amount of molar relationship correction was $1.8 \mathrm{~mm}$. The skeletal correction was $105 \%$, leaving $-0.1 \mathrm{~mm}$ or $-5 \%$ attributed to dental movements. Calculations are shown for the overjet and molar relationship correction above. Diagrams are also provided to illustrate the anterior and posterior movements of the maxilla, mandible, maxillary incisors, mandibular incisor, maxillary molars, and mandibular molars (Figures 5 and 6 ). A pitchfork analysis diagram describing the skeletal and dental components of overjet and molar correction is shown in Figure 7. 
Figure 7: Pitchfork Analysis for Overjet and Molar Correction T2-T1
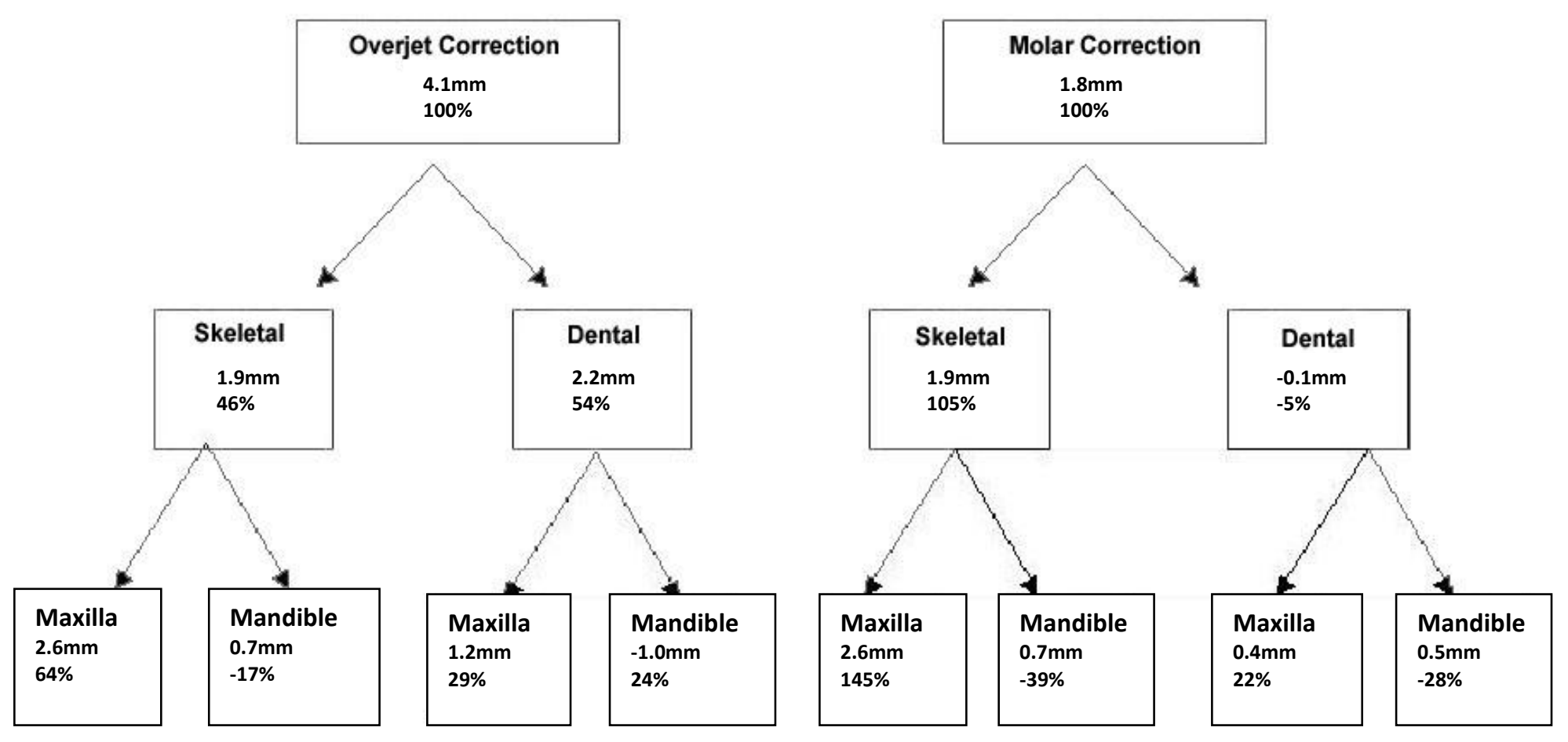
T3-T2:

\begin{tabular}{|cccc|}
\hline Overiet Correction: & & Molar relationship: & \\
Skeletal Contribution: & & Skeletal Contribution: & \\
1) Maxilla & 1.5 & 1) Maxilla & 1.5 \\
2) Mandible & 3.7 & 2) Mandible & 3.7 \\
Dental Contribution: & & Dental Contribution: & \\
3) Mx incisor & 1.8 & 3) Mx molar & 1.4 \\
4) Md incisor & -0.1 & 4) Md molar & -0.6 \\
\hline
\end{tabular}

Overjet Correction $=$ Maxilla + Mx incisor - Mandible - Md incisor

Overjet Correction $=1.5+1 \cdot 8-3 \cdot 7-(-.1)=-0.3$

Figure 8: Components of Overjet Correction T3-T2

\section{Overjet Correction \\ of $\quad-0.3 \mathrm{~mm}$}

Skeletal contribution

$=\quad-2.2 \mathrm{~mm}$

Dental contribution

$=1.9 \mathrm{~mm}$

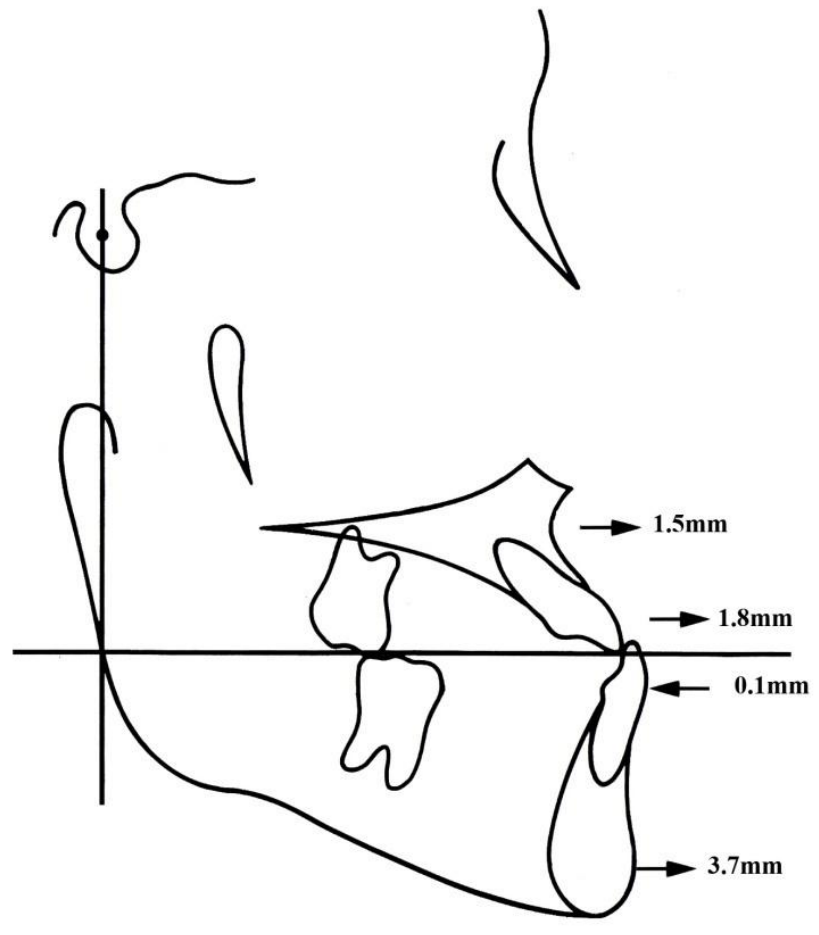


Molar Relationship Correction = Maxilla + Mx molar - Mandible - Md

Molar Relationship Correction $=1.54+1.31-3.7-(-.61)=-0.24$

Figure 9: Components of Molar Correction T3-T2
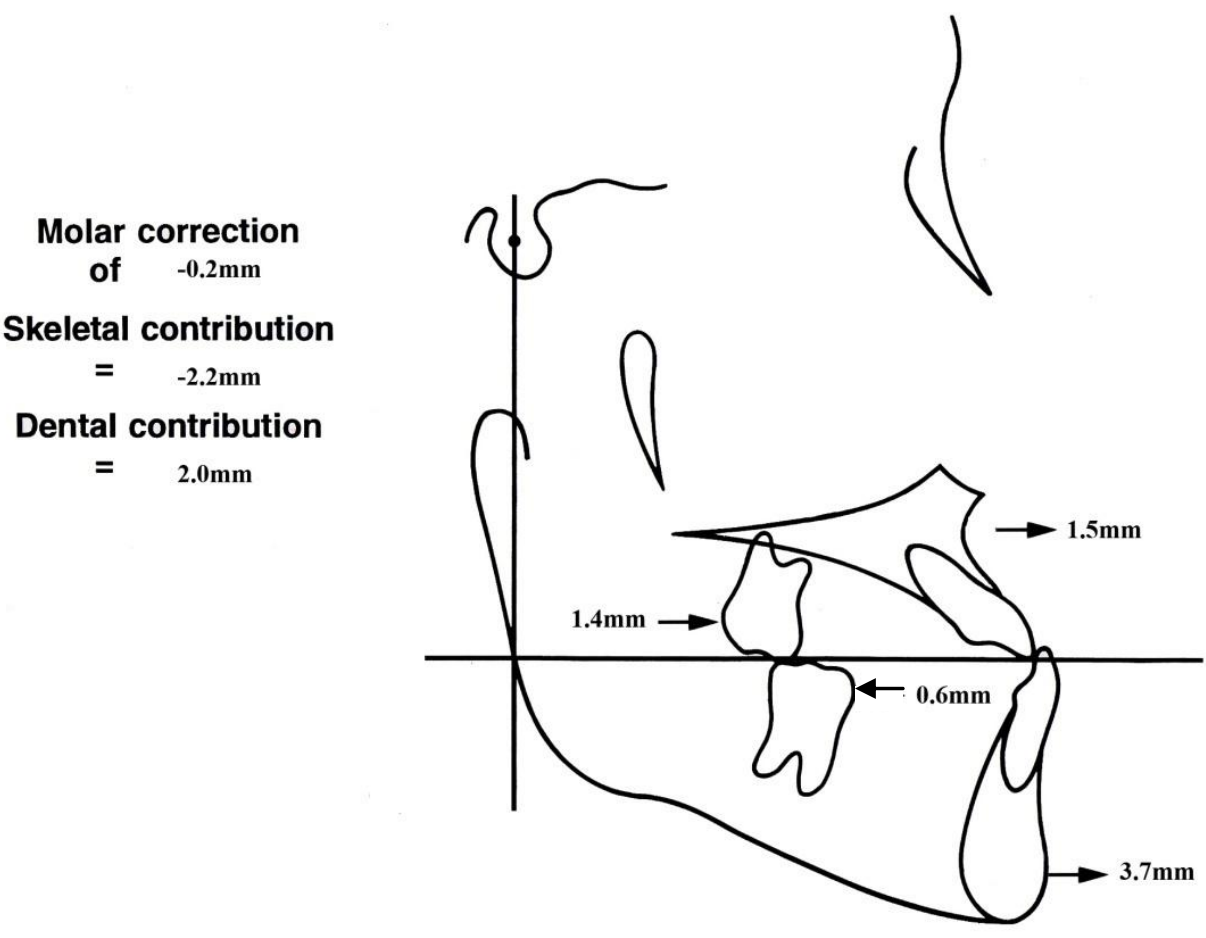

The amount of skeletal and dental contribution to the overjet and molar relationship correction for T3-T2 was calculated using the formulas in Table 7. The amount of overjet correction was $-0.3 \mathrm{~mm}$. The amount of correction attributed to skeletal movement was -2.2 $\mathrm{mm}$ or $-733 \%$ and the amount of dental correction was $1.9 \mathrm{~mm}$ or $633 \%$. The amount of molar relationship correction was $-0.2 \mathrm{~mm}$. The skeletal correction was $-2.2 \mathrm{~mm}$, or $-1100 \%$; leaving 
$2.0 \mathrm{~mm}$ or $1000 \%$ attributed to dental movements. Calculations are shown for the overjet and molar relationship correction above. Diagrams are also provided to illustrate the anterior and posterior movements of the maxilla, mandible, maxillary incisors, mandibular incisor, maxillary molars, and mandibular molars (Figures 8 and 9). A pitchfork analysis diagram describing the skeletal and dental components of overjet and molar correction is shown in Figure 10.

Figure 10: Pitchfork Analysis for Overjet and Molar Correction T3-T2
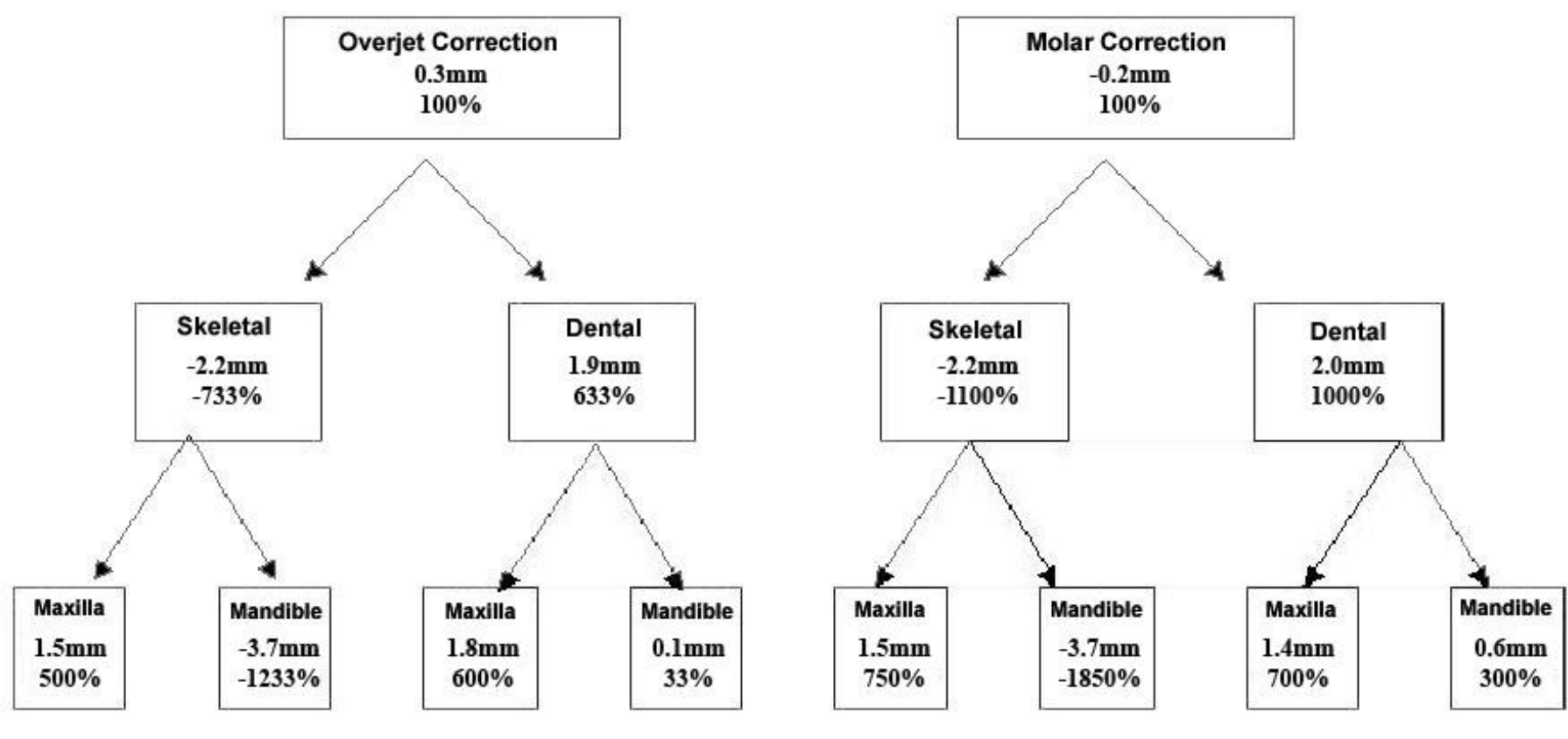
T3-T1:

\begin{tabular}{|cccc|}
\hline Overiet Correction: & & Molar relationship: & \\
Skeletal Contribution: & & Skeletal Contribution: & \\
1) Maxilla & 4.2 & 1) Maxilla & 4.2 \\
2) Mandible & 4.4 & 2) Mandible & 4.4 \\
Dental Contribution: & & Dental Contribution: & \\
3) Mx incisor & 2.9 & 3) Mx molar & 1.6 \\
4) Md incisor & -1.1 & 4) Md molar & -0.1 \\
\end{tabular}

Overjet Correction $=$ Maxilla + Mx incisor - Mandible - Md incisor

Overjet Correction $=4 \cdot 2+2 \cdot 9-4 \cdot 4-(-1 \cdot 1)=3.8$

Figure 11: Components of Overjet Correction T3-T1
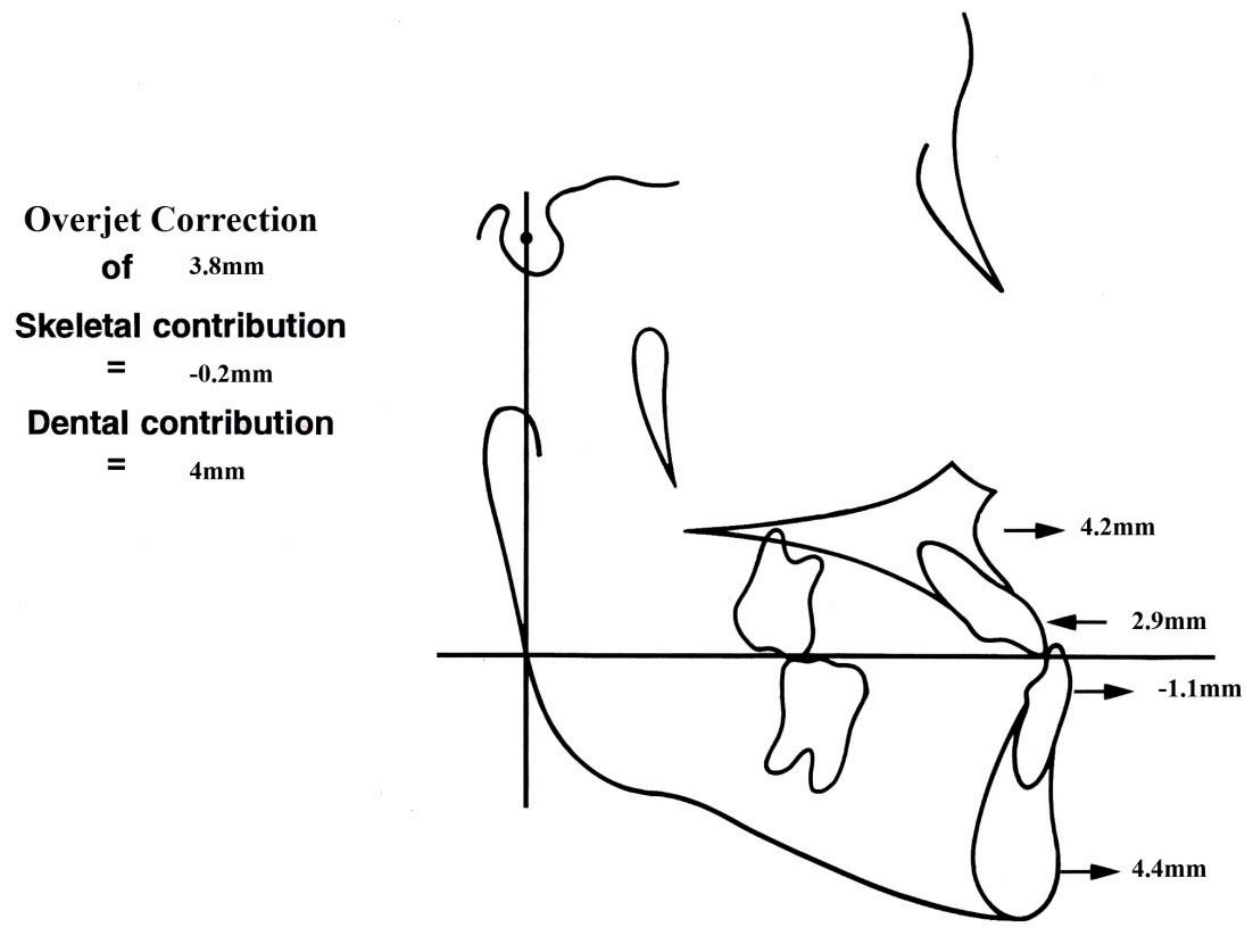
Molar Relationship Correction = Maxilla + Mx molar - Mandible - Md

Molar Relationship Correction $=4 \cdot 2+1 \cdot 6-4 \cdot 4-(-0.1)=1.5$

Figure 12: Components of Molar Correction T3-T1
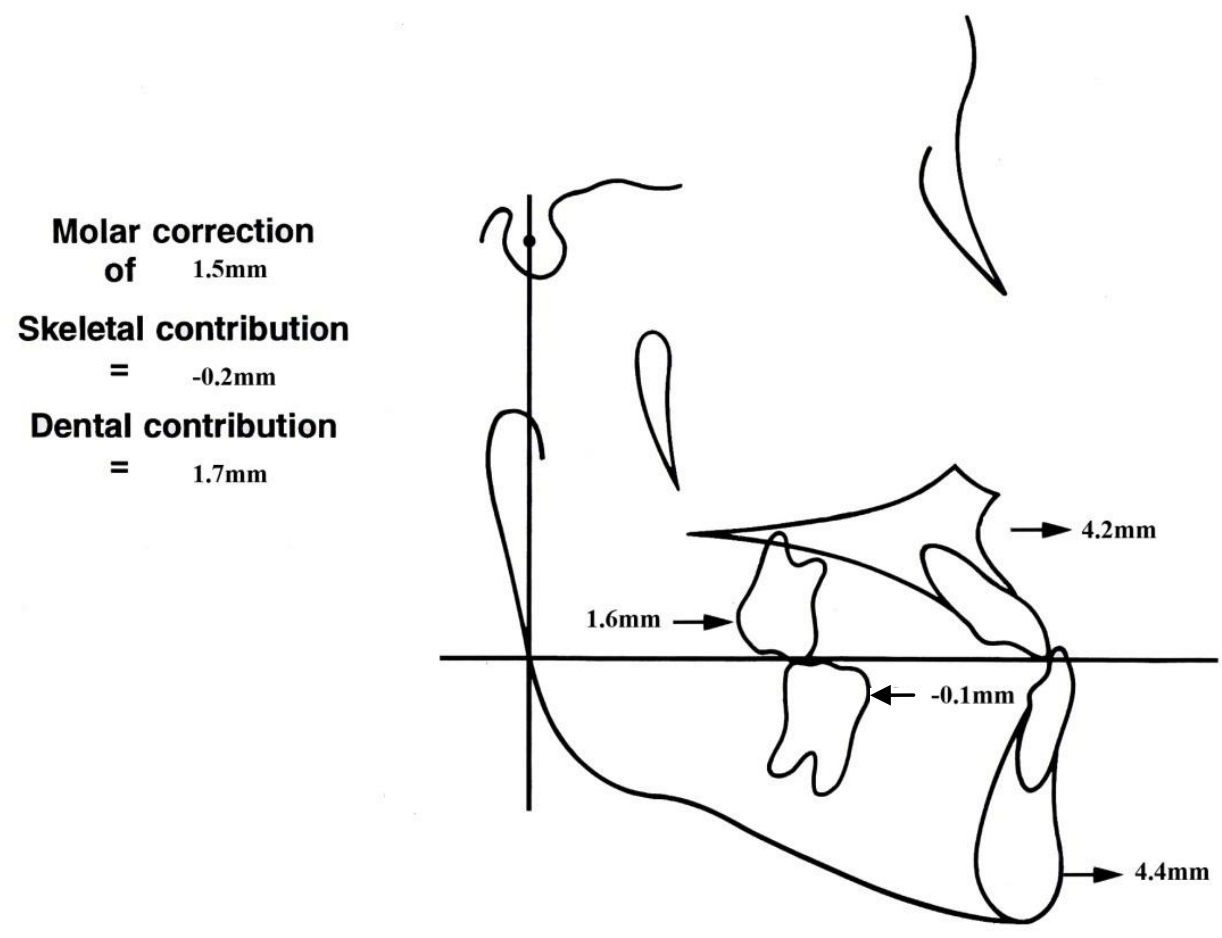

The amount of skeletal and dental contributions for T3-T1 net overjet and net molar relationship correction were calculated using the formulas in Table 7. This T3-T1 shows the net change that occurred over the length of the study which was 31 months. The amount of net overjet correction was $3.8 \mathrm{~mm}$. This measurement is the result of the dental incisor correction being $4 \mathrm{~mm}$ while the skeletal contributions were $-0.2 \mathrm{~mm}$. Reviewing the dental movements, 
the maxillary incisors moved forward $2.9 \mathrm{~mm}$ and the mandibular incisors retruded $1.1 \mathrm{~mm}$ resulting in a total dental correction of $4 \mathrm{~mm}$. The net molar correction was $1.5 \mathrm{~mm}$. The maxillary molar moved forward $1.6 \mathrm{~mm}$ and the mandibular molar moved back $0.1 \mathrm{~mm}$ resulting in a net dental correction for the molars of $1.7 \mathrm{~mm}$. Diagrams and illustrations of these findings are found above. A pitchfork analysis describing the net skeletal and dental contributions to overjet and molar relationship correction is shown in the figure below.

Figure 13: Pitchfork Analysis for Overjet and Molar Correction T3-T1
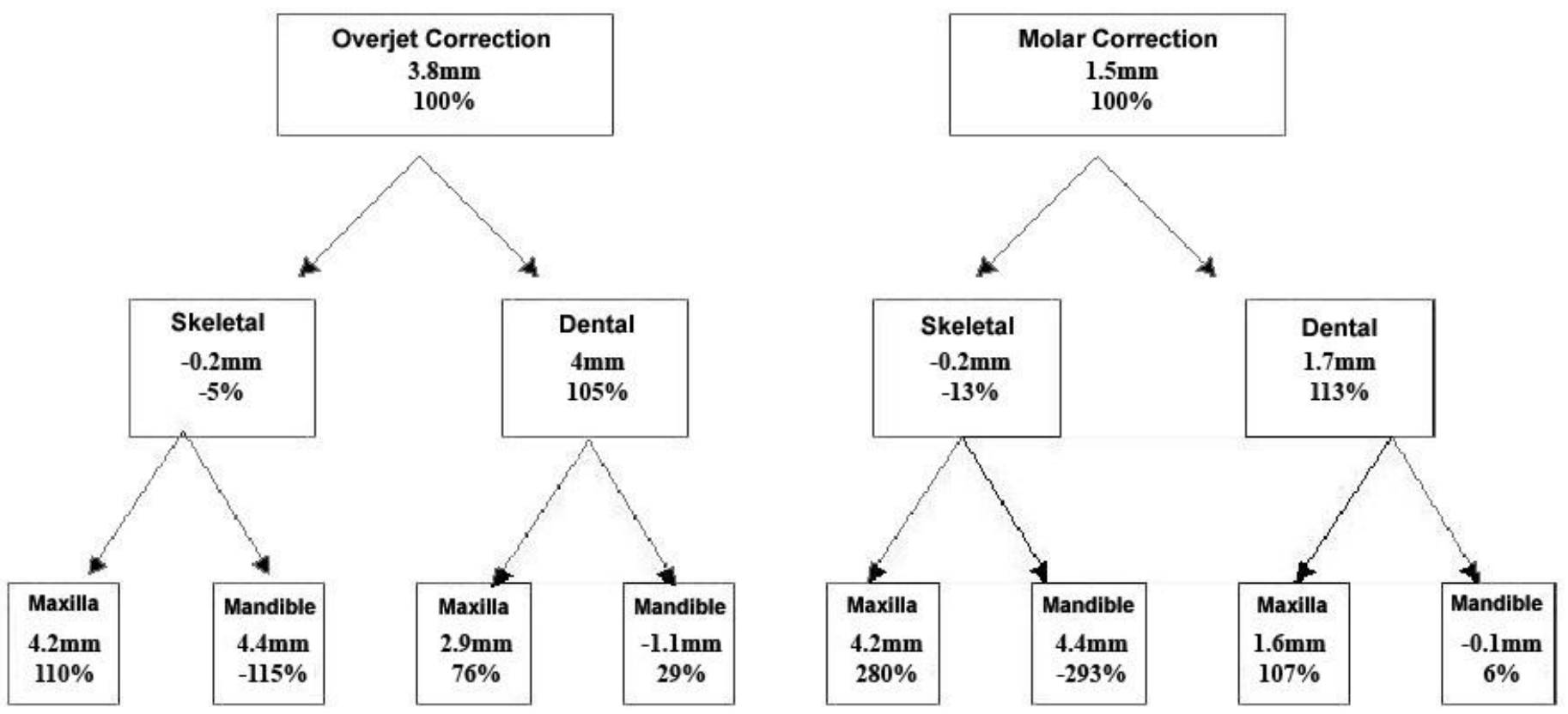


\section{Chapter V: Discussion}

This research project was completed using patients treated at a young age with a Modified Hyrax Expander designed by Dr. Kiebach and Facemask Treatment. It shows the skeletal movements achieved at a young age and also shows the stability of these movements 2 years post-treatment. The maxilla has been shown to be in a retrusive position at an early developmental age, so early treatment is advocated. ${ }^{48}$ Previous investigators, such as Saadia et. al., Turley, Baccetti et. al., and Kapust have found that early treatment produces greater, faster results with improved compliance. The ages in the early treatment groups were from 3 to 7 years of age. They found that changes were almost twice what older groups between 10 and 14 years gained. ${ }^{5,44,45}$ The ages compared with this study group were somewhat different. The youngest treated age for this study was 4 years 4 months with an average of 6 years 2 months. The oldest age was 10 years 4 months which falls within the classified older group in previous research completed. Although the oldest age group in this study was over 10 years of age, the CVM was 1 showing the study group had similar skeletal ages.

Guyer et al found that longitudinal data on Class III subjects showed them to have an average maxillary growth of less than $1 \mathrm{~mm}$ per year and mandibular growth of 3-4.5 $\mathrm{mm}$ per year. This study showed an average maxillary growth of $1.6 \mathrm{~mm}$ per year and an average mandibular growth of $1.7 \mathrm{~mm}$ per year. This shows a vastly different skeletal growth pattern between our treated group and the control study conducted by Guyer et al. ${ }^{5}$

Franchi et. al. investigated treatment timing for RME/FM. He compared early treatment including deciduous and early mixed dentition with late treatment that were in the late mixed 
dentition with erupting canines and premolars. He found that a significant maxillary movement of about $2 \mathrm{~mm}$ was maintained in the early treatment group. ${ }^{12}$ In our study, results following active treatment showed a forward movement of the maxilla of about $2.6 \mathrm{~mm}$ which supports previous findings. The mandibular forward movement was $0.7 \mathrm{~mm}$ during active treatment. This calculates to an average mandibular growth of less than $1 \mathrm{~mm}$ per year. Comparing this to the average mandibular growth in subjects not undergoing treatment which is approximately 3$4.5 \mathrm{~mm}$ of mandibular growth per year, you will find a significant difference between the two. The net changes found in this study showed a forward movement of the maxilla of $4.2 \mathrm{~mm}$ between T1 and T3 time points. The mandible, however, did "catch up" with the maxilla having a total forward movement of $4.4 \mathrm{~mm}$. The mandible outgrew the maxilla, but only slightly, indicating that a maxillary orthopedic change was achieved and maintained.

Franchi et al also found that early treatment maintained a maxillary/mandibular skeletal relationship within $1 \mathrm{~mm}$ because of the significant favorable skeletal contributions of the maxilla and mandible from RME/FM treatment. ${ }^{18}$ This study also supports these previous findings because the total skeletal differential in growth of the maxilla and mandible over the 31 months of observation was that the mandible outgrew the maxilla by only $0.2 \mathrm{~mm}$.

The average treatment age for this research group was 6 years 2 months at the beginning of treatment. The 23 samples ranged from 4 years 4 months to 10 years 4 months. During treatment, the overjet correction attained was $4.1 \mathrm{~mm}$. Most of this correction was maintained with a final overjet correction of $3.8 \mathrm{~mm}$. This shows that the achieved results were stable over the approximate 2 year post-treatment time span. The molar correction achieved 
during treatment was $1.8 \mathrm{~mm}$ and the molar correction 22 months later was an average of 1.5 $\mathrm{mm}$. The molar correction was stable after the appliances were removed over approximately 2 years.

The radiographs were traced by the same examiner to reduce error. The method of cephalometric analysis by Pancherz ${ }^{22}$ was reliable and the error that did occur was within acceptable parameters. The angular measurements showed that the Palatal Plane, Occlusal Plane, and Mandibular Plane did not change significantly during treatment. The only significant change occurred between T2 and T3 time points with the Mandibular Plane. Results showed a decrease in the Mandibular Plane Angle which increased again for the time points T1 to T3. This indicates that the mandibular plane Angle changed with treatment, but reverted back toward pre-treatment averages by the 2 year post-treatment cephalogram.

Skeletal maturation and age differentiation was not addressed in this project because the entire study sample size had a CVM I skeletal age for time point T1. There would have been no difference in the results, so all patients were pooled together.

The research conducted evaluated an active treatment time of 9 months and a follow up of approximately 2 years after active treatment. This was a long-term observational study which was able to show skeletal and dental stability over time. The Wits measurement before treatment was -4.2 and was -2.5 after 31 months of treatment and observation. This shows that the skeletal correction achieved at a young age was maintained over the 2 years of observation. Results support previous research advocating early treatment for Class III malocclusions. 


\section{Chapter VI: Summary and Conclusions}

\section{Summary}

The purpose of this study was to investigate skeletal and dental changes associated with Dr. Kiebach's Modified Hyrax Expander and Facemask treatment performed at an early age. This was an observational study which consisted of 23 patients treated by one clinician.

The cephalometric study implored and analysis described by Byork ${ }^{21}$ and Pancherz. ${ }^{22}$ Angular cephalometric measurements were completed as well. A matched pairs t-test was used to evaluate the findings. The following hypothesis were tested:

1. The patients treated with Dr. Kiebach's Modified Hyrax Expander and facemask therapy will not show significant dental movements.

2. The patients treated with Dr. Kiebach's Modified Hyrax Expander and facemask therapy will not show significant skeletal movements.

\section{Conclusions}

The hypothesis was rejected as the following statistically significant changes were observed:

1. From T1 to T2: Sagittal movements were all statistically significant accept growth at Pogonion and lower incisor inclination. Vertical movements were all statistically significant. Statistically significant movements for the angular measurements were SNB, ANB, Is/SNL and li/ML. 
2. From T2 to T3: All sagittal movements were statistically significant accept the molar relationship measurement. Vertically significant measurements were Nasion-A point, IsNL, li-ML, and Mic-ML. For the angular measurements, ANB, SNL-ML, Is/SNL, li/ML, and Is/li were statistically significant.

3. From T1 to T3: All movements were statistically significant accept Overbite, SNA, SNLNL, SNL-ML, and SNL-OLs.

The net overjet and molar relationship movements showed a forward maxillary skeletal movement of $2.6 \mathrm{~mm}$ in 9 months with RME/FM treatment. There was a continuation of forward maxillary movement the next 22 months of $1.5 \mathrm{~mm}$. The results show a combination of skeletal and dental contributions to the Class III malocclusion treated. The treatment at a young age showed stable results post treatment.

Overall, the net overjet corrections observed by T2-T1 were $46 \%$ skeletal and $54 \%$ dental. However, comparing the T3-T1 overjet measurements, the skeletal contribution was $-5 \%$ and the dental contributions were $105 \%$. This shows that over time, the class III growth pattern remained and the skeletal corrections achieved were masked over time by a continued Class III growth. The same is true for the net molar correction. For T2-T1, the net molar correction was $105 \%$ skeletal and $-5 \%$ dental. By the time the 22 month post-treatment cephalogram was taken for T3-T1, the skeletal correction was $-13 \%$ and the dental correction was $113 \%$. Skeletal changes included forward movement of the maxilla and limited movement of the mandible for T2-T1. Dental changes for the same time points included proclination of the maxillary incisors while the mandibular incisors retroclined. Maxillary molars mesialized and average of $0.4 \mathrm{~mm}$ 
while the mandibular molars continued to move forward $0.5 \mathrm{~mm}$. The net change (T3-T1) shows the maxilla moved forward $4.2 \mathrm{~mm}$ and the mandible moved forward $4.2 \mathrm{~mm}$. The maxillary incisors tipped labially $2.9 \mathrm{~mm}$ while the mandibular incisors tipped lingually $1.1 \mathrm{~mm}$. The maxillary molars mesialized $1.6 \mathrm{~mm}$ and the mandibular molars distalized $0.1 \mathrm{~mm}$. 


\section{Chapter VII: Recommendations for future research}

1. The treatment group should be compared to a control group matched in skeletal age and also traced by the same investigator.

2. This study should have a bigger treatment group sample.

3. The sample should have a more narrow age range rather than $\mathrm{T} 1$ ages varying from 4 years 4 months to 10 years 4 months.

4. The T3 long term results should be more concise rather than having a wide range for T2-T3. This time measurement varied from 3 months to over 4 years. A more consistent post-treatment reference would give the reader a more reliable result.

5. A 3D cone beam study on patients treated with the Modified Hyrax Expander and Facemask treatment would allow the study of the effects of the devices in 3 dimensions. 


\section{Reference List:}

1. Prevalence of malocclusion and orthodontic treatment need in the United States:

Estimates from the NHANES III Survey. Int J Orthod 1998;13 (2):97-106

2. Ngan P: Early treatment of Class III malocclusion: Is it worth the burden? Am J Orthod Dentofac Orthop 2005; 129:S82-S85

3. Guyer EC, Ellis EE, McNamara JA et al: Components of Class III malocclusions in juveniles and adolescents. Angle Orthod 1986 56:7-30

4. Bailey L, Turvey T, Sarver D, Proffit W, Chapter 16: Class III Problems, Proffit W, White R, Sarver D: Contemporary Treatment of Dentofacial Deformity. 2003; 507-555

5. Baccetti, T: Craniofacial changes in Class III malocclusion as related to skeletal and dental maturation. Am J Orthod Dentofac Orthop 2007; 132(2):171-178

6. Vaughn G: The effects of maxillary protraction therapy with or without rapid palatal expansion: A prospective, randomized clinical trial. Am J Orthod Dentofac Orthop 2005; 128 (3): 299-309

7. Turley: Managing the developing Class III malocclusion with palatal expansion and facemask therapy. Am J Orthod Dentofac Orthop 2002; 122(4):349-352

8. Baccetti, T: Skeletal effects of early treatment of Class III malocclusion with maxillary expansion and facemask therapy. Am J Orthod Dentofac Orthop 1998; 113(3):333-343

9. Haas AJ: Treatment of maxillary deficiency by opening the midpalatal suture. Angle Orthod 1965;65:200-217

10. Haas AJ: Palatal expansion: just the beginning of dentofacial orthopedics. Am J Orthod $1970 ; 57: 219-255$ 
11. McNamara JA Jr, Brudon WL. Orthodontic and orthopedic treatment in the mixed dentition. Ann Arbor, Mich.: Needham Press, 1993

12. Franchi L; Postpubertal assessment of treatment timing for maxillary expansion and protraction therapy followed by fixed appliances. Am J Orthod Dentofac Orthop 2004; $126(5): 555-568$

13. Proffit WR, Fields HW Jr. Contemporary orthodontics $3^{\text {rd }}$ ed. Saint Louis: Mosby; 2000

14. McNamara JA Jr, Brudon WL. Orthodontics and dentofacial orthopedics. Ann Arbor: Needham Press; 2001

15. Vaik HS. Clinical results of maxillary protraction in Korean children. Am J Orthod Dentofac Orthop 1995; 108:583-592

16. Merwin D, Ngan P, Hagg U, YiuC, Wei SH. Timing for effective application of anteriorly directed orthopedic force to the maxilla. Am J Orthod Dentofac Orthop 1997;112:292-9

17. Kapust AJ, Sinclair PM, Turley PK. Cephalometric effects of facemask/expansion therapy in Class III children: a comparison of three age groups. Am J orthod Dentofac orthop $1998 ; 113: 204-12$

18. Saadia M, Torres E. Sagittal changes after maxillary protraction with expiation in Class III patients in the primary, mixed, and late mixed dentitions: a longitudinal retrospective study. Am J orthod Dentofac Orthoped 2000; 117:669-80

19. Baccetti T, Franchi L, McNamara JA Jr. Treatment and post-treatment craniofacial changes after rapid maxillary expansion and facemask therapy. Am J Orthod Dentofac Orthop 2000; 118:404-13 
20. Cha KS. Skeletal changes of maxillary protraction in patients exhibiting skeletal Class III malocclusion: a comparison of three skeletal maturation groups. Angle orthod $2003 ; 73: 26-35$

21. Bjork A: The face in Profile: An anthropological X-ray investigation of Swedish Children and Conscripts. Lund: Berlingska Boktrycheriet 1947; 40: 58

22. Pancherz $\mathrm{H}$ : The mechanism of Class II correction in Herbst appliance treatment, a cephalometric investigation. Am J Orthod 1982; 82: 107-113

23. Ngan P: Early Timely Treatment of Class III Malocclusion. Seminars in Orthod:11:140145, 2005

24. Newman GV: Prevalence of malocclusion in children 6-14 years of age and treatment in preventable cases. Am J Dent Assoc 52:566-575, 1956

25. Thilander B, Myrberg N: The prevalence of malocclusion in Swedish school children. Scand J Dent Res 81:12-20, 1973

26. Tschill P, Bacon W, Sonko A: Malocclusion in the deciduous dentition of Caucasian children. Eur J Orthod 19:361-367, 1997

27. Ishii H, Morita S, Takeuchi Y, et al: Treatment effect of combined maxillary protraction and chincap appliance in severe skeletal Class III cases. Am J Orthod Dentofacial Orthop $92: 304-312,1987$

28. Allwright WC, Burndred WH: A survey of handicapping dentofacial anomalies among Chinese in Hong Kong. Int Dent J 14:505-519, 1964

29. Lauweryns I, Carels C, Vlietinck R. The use of twins in dentofacial genetic research. Am J Orthod Dentofac Orthop 103:33-38,1993 
30. Proffit WR, Fields HW Jr., Sarver DM, Contemporary orthodontics $4^{\text {th }}$ ed. 141-147 Saint Louis: Mosby Elsevier; 2007

31. McGuigan DG. The Hapsburgs. London, WH Allen, 1966

32. Lee KG, RyuYK, Park YC, Rudolph DJ: A study of holographic interferometry on the initial reaction of maxillofacial complex during protraction. Am J Orthod Dentofac Orthoped 1997; 111:623-32

33. Miyajima K, McNamara JA Jr, Kimura T, Murata S, lizuka T. An estimation of craniofacial growth in the untreated Class III female with anterior crossbite. Am J Orthod Dentofacial Orthop 1997; 112:425-34

34. Enrich RE, Brodie AG, Blayney JR: Prevalence of Class I, Class II, and Class III malocclusions in an urban population: An epidemiological study. J Dent Res $1964 ; 44: 947$

35. Battagel, JM. The aetiological factors in Class III malocclusion. Eur J Orthod 1993; 15(5): $347-370$

36. McIntyre GT: Treatment planning in Class III Malocclusion. Dent Update 2004; JanFeb 31(1): 13-20

37. Bagatel JM: Class III malocclusion; postretention findings. European J of Orthod $1993 ; 15: 45-55$

38. Murakami C, Hiyama S, Ohayama K: Craniofacial morphology of skeletal Class III patients. World J Orthod 2005; Spring; 6(1):51-60

39. Macdonald, KE, Kapust AJ, Turley, PK: Cephalometric changes after the correction of Class III malocclusion with maxillary expansion/facemask therapy. Am J Orthod Dentofac Orthop 1999, 116(1):13-24 
40. Graber TM: Orthodontics: principles and practice. Philadelphia:WB Saunders Company; 1966

41. McNamara JA: Mixed dentition treatment. In: Graber TM, Vanarsdall RL, eds. Orthodontics. Current principles and techniques, $2^{\text {nd }}$ ed. St. Louis: Mosby Year Book, 1994; 507-541

42. Tanne K, HiragaJ, Sakuda M: Effects of directions of maxillary protraction forceson biomechanical changes in craniofacial complex. Europ J Orthod 1989;11:382-395

43. Ngan P: Biomechanics of maxillary expansion and protractioin in Class III patients. Am J Orthod Dentofacial Orthop 2002, 121:582-583

44. Saadia M, Torres E: Sagittal changes after maxillary protraction with expansion in Class III patients in the primary, mixed and late mixed dentitions: A longitudinal retrospective study. Am J Orthod Dentofac Orthop 2000; 117(6):669-680 


\section{Appendix A}

Treatment age for T1, T2 and T3

\begin{tabular}{|c|c|c|}
\hline \multicolumn{3}{|c|}{ Treatment Age } \\
\hline T1 & T2 & T3 \\
\hline $4 y 11 m$ & $5 y 7 m$ & $6 y 1 m$ \\
\hline $7 y 8 m$ & $9 y 5 m$ & $11 y 6 m$ \\
\hline $4 y 6 m$ & $5 y 6 m$ & $6 y 10 m$ \\
\hline $4 y 10 m$ & $5 y 6 m$ & $7 y 5 m$ \\
\hline $10 y 4 m$ & $11 y 2 m$ & $11 y 7 m$ \\
\hline $6 y 6 m$ & $7 y 2 m$ & $9 y 10 m$ \\
\hline $5 y 3 m$ & $6 y 1 m$ & $7 y 9 m$ \\
\hline $5 y$ & $5 y 5 m$ & $7 y 6 m$ \\
\hline $8 y 2 m$ & $9 y 1 m$ & $11 y 4 m$ \\
\hline $10 y 1 m$ & $10 y 7 m$ & $12 y 6 m$ \\
\hline $4 y 1 m$ & $6 y 2 m$ & $8 y 8 m$ \\
\hline $6 y 5 m$ & $7 y 9 m$ & $10 y 2 m$ \\
\hline $5 y 7 m$ & $6 y 1 m$ & $8 y 11 m$ \\
\hline $6 y 10 m$ & $7 y 5 m$ & $9 y 8 m$ \\
\hline $5 y 2 m$ & $5 y 9 m$ & $7 y 7 m$ \\
\hline $8 y 7 m$ & $8 y 10 m$ & $9 y 11 m$ \\
\hline $6 y 6 m$ & $6 y 9 m$ & $7 y 11 m$ \\
\hline $4 y 4 m$ & $5 y 2 m$ & $7 y 4 m$ \\
\hline $4 y 11 m$ & $5 y 7 m$ & $6 y 6 m$ \\
\hline $5 y 1 m$ & $5 y 11 m$ & $9 y 11 m$ \\
\hline $6 y 2 m$ & $7 y 2 m$ & $10 y 10 m$ \\
\hline $5 y 2 m$ & $5 y 10 m$ & $6 y 5 m$ \\
\hline $5 y 2 m$ & $6 y 2 m$ & $7 y 1 m$ \\
\hline
\end{tabular}




\title{
TREATMENT OF CLASS III MALOCCLUSION IN THE PRIMARY AND EARLY MIXED DENTITION USING THE KIEBACH APPLIANCE AND PROTRACTION FACEMASK
}

\author{
Erica W Reed, DDS \\ Thesis Submitted to the \\ School of Dentistry at West Virginia University \\ In partial fulfillment of the requirements \\ For the degree of Master of Science
}

APPROVAL OF EXAMINING COMMITTEE

Peter Ngan, D.M.D., Chairman

Chris Martin, D.D.S., M.S.

Thomas Razmus, D.D.S., M.S.

Date

John $\mathrm{H}$. 